\title{
The Geographic Distribution of Human Capital: Measurement of Contributing Mechanisms
}

\author{
Peter McHenry \\ College of William and Mary
}

College of William and Mary

Department of Economics

Working Paper Number 92

May 2010

\footnotetext{
* I am grateful to Joe Altonji, Fabian Lange, Pat Kline, and Melissa Tartari for advice about my research. For additional helpful comments, I thank Matt Johnson, Lisa Kahn, Paul Schultz, and seminar participants at the College of William and Mary, University of Kentucky, Federal Reserve Bank of Cleveland, Federal Trade Commission, Yale University, and the Society of Labor Economists 2009 meetings ** Department of Economics, College of William and Mary, P.O. Box 8795, Williamsburg, VA 23187; pmchenry@wm.edu; http://wmpeople.wm.edu/site/page/pmchenry
} 
COLLEGE OF WILLIAM AND MARY

DEPARTMENT OF ECONOMICS

WORKING PAPER \#92

MAY 2010

\title{
The Geographic Distribution of Human Capital: Measurement of Contributing Mechanisms
}

\begin{abstract}
This paper investigates how the geographic distribution of human capital evolves over time. With U.S. data, I decompose generation-to-generation changes in local human capital into three factors: the previous generation's human capital, intergenerational transmission of skills from parents to their children, and migration of the children. I find evidence of regression to the mean of local skills at the state level and divergence at the commuting zone level. Labor market size, climate, local colleges, and taxes affect local skill measures. Skills move from urban to rural labor markets through intergenerational transmission but from rural to urban labor markets through migration.
\end{abstract}

JEL Codes: R23, J61, J11

Keywords: Migration, Intergenerational transmission, Regional labor markets

Peter McHenry

Department of Economics

College of William and Mary

Williamsburg, VA 23187-8795

pmchenry@wm.edu 


\section{Introduction}

The variance of skill levels across U.S. labor markets is large. Table 1 shows the labor markets with the highest and lowest percent residents with a college degree in the 2000 Census. The gap between the most educated places like the nation's capital, San Francisco, and Boston and the least educated places like rural Appalachia is remarkable.

A recent economics literature suggests that skills generate substantial benefits for local economies. The focus tends to be on the effects of local skill differences rather than how those skill differences arose. For example, Moretti (2004a) argues that an increase in the percent of a city's residents with a college degree increases wages of all its residents, so education has external benefits. ${ }^{1}$ Researching another effect, Glaeser and Saiz (2003) show that the percent of a city's residents with a college degree is positively correlated with city population growth throughout the 20th century. They provide evidence that higher-skilled cities experience more productivity growth, and they argue that local skills enable cities to adapt to changing economic environments.

Consistent with these findings, local governments in the U.S. attempt to retain and attract skilled workers. An example of their efforts is Georgia's HOPE scholarship, which reduces the cost of attending Georgia colleges for academically successful Georgia high school graduates. Several states have subsequently enacted similar scholarship programs with the explicit goal of retaining local talent.

Despite the perceived benefits from local skills, economists know relatively little about the process that determines the observed geographic distribution of skill. In particular, we do not know much about the persistence of skill inequality across labor markets over time or about the mechanisms underlying this persistence. In addition, we do not have a clear sense for what local characteristics predict that a location will have a high or low level of skill.

This paper contributes empirical evidence about the geographic distribution of skill in

\footnotetext{
${ }^{1}$ Other papers about the same topic include Rauch (1993), Acemoglu and Angrist (2000), and Ciccone and Peri (2006). Lange and Topel (2006) call into question the identification strategies used in this literature but leave open the possibility that education has external benefits.
} 
the U.S. and a framework for understanding the determinants of this distribution. Three factors determine the human capital in a local labor market at a point in time: the human capital of the previous generation, the intergenerational transmission of skill from parents in the previous generation to their children, and migration of differently skilled children to adult locations. I assess how intergenerational transmission and migration affect the persistence over time of labor market skill inequality. I also identify labor market characteristics that predict local skill levels.

I begin with a statistical decomposition of state differences in skills using the U.S. Census. I use a predicted earnings index to categorize workers into skill categories and take as my local skills measure the local ratio of high-skilled to low-skilled populations. I take the state as the location definition, since this is the least aggregated birth location identified in the Census. For each state, I measure the skills of a parent generation residing in the state, of the next generation born in the state, and of the second generation residing in the state as adults (natives who stayed and in-migrants). I find evidence of mean reversion in state skills through intergeneration transmission; that is, states with the highestand lowest-skilled parents tend to have children with skills closer to the national mean level of skills.

Of course, the Census has weaknesses for this exercise. The most important weakness is that states are poor proxies for labor markets, which are the geographic units of interest for understanding local production and consumption. Many states contain several heterogeneous local labor markets (for example, New York), and some labor markets cross state lines (eg, Kansas City). So, analysis at the state level conceals important skill movements across locations, especially between rural and urban labor markets.

To remedy this, I use detailed location data for respondents to the National Education Longitudinal Study of 1988 (NELS:88), which is a nationally representative sample of U.S. resident students in the eighth grade in 1988. The NELS:88 also provides richer data on individual skills and provides data on linked parent and child skills. In order to use the relatively small sample size of the NELS:88 to study skill distributions of all U.S. labor 
markets, I add structure to the local skill decomposition framework.

The additional structure is a model that explains the geographic distribution of human capital as the outcome of a dynamic process wherein parents with different skills choose residence locations, they pass skills to their children, and their children choose their own residence locations. The model shows that selective net migration responds to local characteristics that affect the local relative demand and supply for high- and low-skilled residents. Estimating the model for states replicates findings in the Census accounting exercise, which increases confidence in the estimation procedure.

I then estimate the model using groups of counties called commuting zones as the labor market definition. The intergenerational transmission mechanism induces regression toward the mean of labor market skills. In contrast, migration of skills toward labor markets with higher parents skills induces a divergence of commuting zone skills. Small and rural labor markets tend to have the lowest skill levels among adults. These small labor markets gain the most skills through intergenerational transmission, but they lose these skill gains as their most-skilled natives leave at the highest rates.

\section{Previous literature}

The previous literature informing us about determinants of the geographic distribution of human capital can be divided into two segments. The first is the study of differences in migration behavior of people with different skills. Differences by skill in migration frequencies, purposes, and destinations affect how migration distributes skills across labor markets. The second and smaller segment describes how education levels vary across locations and identifies location characteristics that are correlated with local education levels.

The main finding of the first literature segment is that more-skilled people are more geographically mobile than less-skilled people. In his survey of the migration literature, 
Greenwood (1997) notes this as a robust finding. ${ }^{2}$ Relatedly, Bound and Holzer (1992) and Wozniak (2006) provide evidence that college graduates are more likely to move in response to local labor demand shocks than those with less schooling. Malamud and Wozniak (2007) argue that the estimated effect of college education on migration frequency is causal. $^{3}$

Another general theme in the literature is that labor market opportunities are more important to higher-skilled migrants than to lower-skilled migrants. Borjas, Bronars, and Trejo (1992) and Dahl (2002) show that higher-skilled individuals tend to sort into labor markets with higher returns to skill. Ham, Li, and Reagan (2006) demonstrate that college graduates who migrate experience wage growth increases, but high school dropouts who migrate experience wage growth decreases. Kodrzycki (2001) uses the NLSY79 to show that recent college graduates tend to move to states with stronger labor markets than their origins. Basker (2003) provides evidence that more-educated migrants are more likely to have a job in hand when migrating than less-educated migrants.

A few papers investigate the determinants of local education levels. One determinant is the local education level in a previous year. Berry and Glaeser (2005) and Moretti (2004b) show that MSAs with higher initial proportions of college-educated residents experience more growth in the proportion of college-educated residents between 1970 and 2000. This implies modest divergence of skill levels across MSAs. Bound, Groen, Kezdi, and Turner (2004) study the effect of flows of graduates from state colleges on later stocks of college educated residents and find evidence of a modest positive relationship. Glaeser, Resseger, and Tobio (2008) find evidence that proximity to Latin America, and the corresponding lower cost of immigrating from Latin America, increases an MSA's population of residents with less than high school education.

\footnotetext{
${ }^{2}$ Many articles show that more education is positively correlated with higher migration frequency. Bowles (1970) shows that the positive relationship between expected income gains from migrating out of the U.S. South and actual outmigration is stronger for people with more years of schooling. Courchene (1970) makes similar findings in Canada. Schultz (1971) shows that local schooling is positively correlated with rural-to-urban migration in Colombia.

${ }^{3}$ McHenry (2008) argues that the effect of low levels of schooling on migration is non-positive. This is consistent with positive correlations between schooling and migration and also with a positive causal effect of schooling on migration at higher levels of schooling (high school and above).
} 
Moretti (2004b) takes a sample of MSAs and regresses the change in percent residents with college degrees between 1990 and 2000 on MSA characteristics. He finds the highest growth in northeastern MSAs. The increase in the MSA college share is positively correlated with 1990 college share, population, and percent employment in high-tech jobs.

Kodrzycki (2000) is the most similar paper to mine. Kodrzycki studies the differences across Census divisions ${ }^{4}$ in percent residents with a college degree. She categorizes regional degree holders into natives who attend local college and stay, migrants who come for college, migrants who come after college, and natives who leave for college but return. Her focus is on New England, and she shows that New England's top rank in education is due mostly to high rates of native college attendance and graduation, rather than migration of college degree holders.

The analysis here adds to the literature in several directions. Instead of measuring skill changes from one adult cohort to the next, it decomposes skill changes into the effects of intergenerational transmission and migration mechanisms. A benefit of doing so is the ability to identify whether policies aimed at native skill acquisition or skilled migration have more potential impact on local skills. This analysis also uses commuting zones to define local labor markets in an economically-meaningful way. In doing so, it highlights the contrast between rural and urban labor markets, which is not common in the literature. In addition, the measurement of skill in this paper is more general than in previous analyses, since it aggregates multiple individual characteristics (including schooling) using weights from earnings functions.

\footnotetext{
${ }^{4}$ The nine Census divisions are collections of states. Their names are New England, Middle Atlantic, East North Central, West North Central, South Atlantic, East South Central, West South Central, Mountain, and Pacific.
} 


\section{A statistical decomposition of state differences in skills}

\subsection{Decomposition of skill supply}

In this section, I decompose the relative supply of skills to a state into three factors: the skill distribution of the previous generation in the state, the intergenerational transmission of skills, and the migration of skills. Let the number of high-skilled adults in location $j$ in generation $g$ be $A_{H j g}$ and the corresponding low-skilled population be $A_{L j g}$. Let the number of high-skilled children in state $j$ in generation $g$ be $C_{H j g}$ and the corresponding low-skilled population be $C_{L j g}$.

The number of adults in a state is the sum of the local children who decided to stay and the people from elsewhere who decided to move to the state. That is,

$$
A_{s j g}=\# \text { Stay }_{s j g}+\# \operatorname{InMig}_{s j g}
$$

for $s=L, H$. Let $P_{s j k g}$ be the probability that an individual with skill $s$ chooses to migrate from state $j$ to state $k$, so $P_{s j j g}$ is the probability of staying in $j$. Then, the number of stayers in $j$ can be expressed as \#Stay ${ }_{s j g}=C_{s j g} P_{s j j g}$ for $s=L, H$. Let the ratio of highto low-skilled adults be $S_{j g}=A_{H j g} / A_{L j g}$ and the ratio of high- to low-skilled children be $K_{j g}=C_{H j g} / C_{L j g}$. 
Using these definitions, the relative skill supply to state $j$ is

$$
\begin{aligned}
& S_{j g}=\frac{A_{H j g}}{A_{L j g}}=\frac{\#_{\text {Stay }_{H j g}}+\# \text { InMig }_{H j g}}{\text { \#Stay }_{L j g}+\# \text { InMig }_{L j g}}
\end{aligned}
$$

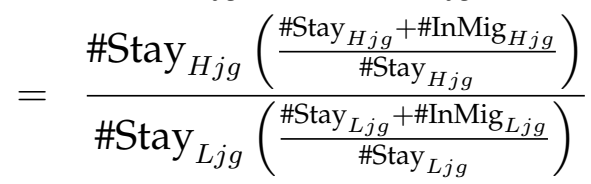

$$
\begin{aligned}
& =\frac{C_{H j g} P_{H j g g}\left(\frac{\text { \#Stay }_{H j g}+\# \operatorname{InMig}_{H j g}}{\# \text { Htay }_{H j g}}\right)}{C_{L j g} P_{L j j g}\left(\frac{\text { \#Stay }_{L j g}+\# \operatorname{InMig}_{L j g}}{\# \operatorname{HSay}_{L j g}}\right)} \\
& =K_{j g} \Lambda_{j g} M_{j g} \\
& =S_{j g-1} \frac{K_{j g}}{S_{j g-1}} \Lambda_{j g} M_{j g} .
\end{aligned}
$$

In the above equation, $\Lambda_{j g} \equiv P_{H j j g} / P_{L j j g}$ is the effect of native retention on the skill ratio in $j . M_{j g}$ is a factor that describes the rate of skill increase through in-migration.

Taking logarithms of Equation 1 yields

$$
\ln \left(S_{j g}\right)=\ln \left(S_{j g-1}\right)+\ln \left(\frac{K_{j g}}{S_{j g-1}}\right)+\ln \left(\Lambda_{j g} M_{j g}\right) .
$$

Equation 2 decomposes the relative supply of skills to state $j$ into factors due to the skill distribution of the previous generation $\left(S_{j g-1}\right)$, the intergenerational transmission of skill from that generation to the next $\left(K_{j g} / S_{j g-1}\right)$, and the migration of skills $\left(\Lambda_{j g} M_{j g}\right)$.

I calculate each element of Equation 2 using U.S. Census data. The major benefit from using Census data is that the samples are large. With these data, the location definition is the state, since that is the most disaggregated level of birthplace identification in the Census. I include Washington, D.C. as a state.

I use a predicted earnings index to measure skills. I take the full-time workers aged 30 to 40 in the 5 percent 2000 Census sample from IPUMS (Ruggles et al. 2004). With this sample, I estimate a regression of the following form:

$$
y_{i j}=\beta X_{i}+\sum_{k} \delta_{k} \mathrm{Occ}_{i k}+\alpha_{j}+\epsilon_{i j}
$$


The dependent variable, $y_{i j}$, is log weekly labor earnings of individual $i$ who lives in state $j$. The vector $X_{i}$ includes characteristics of individual $i$ : sex, race, a quadratic in age, and indicators for completed schooling categories. The other regressors are indicators for three-digit occupation $\left(\mathrm{Occ}_{i k}\right)$ and indicators for state of residence. The state of residence intercepts capture state differences in wages due to various factors, including cost of living.

Using coefficients from OLS estimation of Equation 3, I predict log weekly labor earnings for all workers, setting the state indicator for New York equal to one and all others to zero. I define a worker as high-skilled if his or her predicted earnings fall in the highest quartile of (national) predicted earnings and low-skilled in the lowest quartile. $S_{j g}$ is the ratio of high-skilled to low-skilled populations living in state $j$ as adults in 2000. $K_{j g}$ is the ratio of high-skilled to low-skilled populations born in state $j$.

The idea behind Equation 3 is that productive characteristics are positively correlated with earnings. The measure of local skills $\left(S_{j g}\right)$ is a proxy for expected local earnings, conditional on characteristics of the local population. One benefit of the earnings regression approach is that it provides a weight for each level of schooling attainment, thus quantifying their relative values. In addition, occupations offering higher wages tend to require higher levels of skill. So, I will infer high skills in people in high-earning occupations. Controls for age reflect earnings increasing with work experience.

The controls for sex and race are not meant to measure skills directly. However, they have predictive power for earnings and thereby help predict local earnings. To the extent that sex and race are correlated with unobserved labor market productivity, it seems right to control for them in the earnings regressions. ${ }^{5}$ The control for sex should not impact the analysis much, since sex ratio does not vary dramatically across locations. Racial proportions vary much more across locations, so the controls for race have a larger effect on the analysis.

I calculate $S_{j g-1}$ using a similar earnings prediction index for an earlier cohort: work-

\footnotetext{
${ }^{5}$ If wage gaps are due to labor market discrimination, then it would be incorrect to control for sex and race.
} 
ers aged 35 to 45 in the 5 percent 1980 Census sample from IPUMS. I use a regression with the same form as Equation 3 to predict log weekly earnings for each member of this older cohort and categorize each member into a quartile of the predicted earnings index. $S_{j g-1}$ is the ratio of high-skilled to low-skilled populations living in state $j$ in 1980.

I calculate $P_{s j j g}$ for $s=L, H$ as the fraction of the skill $s$ population born in $j$ who are also living in $j$ in 2000. I then calculate the relative native retention rate for each state: $\Lambda_{j g}=P_{H j j g} / P_{L j j g}$. I also calculate the effect of in-migration on the state skill ratio as $M_{j g}=S_{j g} /\left(K_{j g} \times \Lambda_{j g}\right)$.

In order for Equation 3 to predict skills accurately, I assume that the error term $\epsilon_{i j}$ does not include interactions between occupation and state of residence. If it did, then the earnings prediction would confuse productivity of a worker's state of residence with the worker's own labor market productivity. I expect productivity differentials between occupation categories to vary across states less the more narrowly occupations are defined. I use the most narrow occupation coding available.

Previous local skill measures used in the economics literature are average years of schooling and percent residents with a college degree. ${ }^{6}$ In the present paper, I adopt a different measure: the ratio of local high-skilled to low-skilled populations, where predicted earnings proxy for individual skill. This measure uses earnings to infer labor market productivity of individual characteristics and thereby captures more variation in skill than schooling measures alone. ${ }^{7}$ Referring to skill types (high and low) simplifies exposition somewhat, relative to using a continuous skill measure. Indeed, most economic models of a geographic distribution of people with heterogeneous skills (eg, Berry and Glaeser (2005), Glaeser and Saiz (2003), Moretti (2004a), and this paper) describe skills with discrete types. However, some of the results below use the local average of (continuous) predicted earnings as an alternative, and these results are the same as with the ratio

\footnotetext{
${ }^{6}$ Acemoglu and Angrist (2000) and Rauch (1993) study the impact of local average years of schooling on residents' individual wages. Moretti (2004a) investigates the impact of an MSA's percent college on its residents' own wages. Moretti (2004b) and Berry and Glaeser (2005) investigate trends in percent college residents of MSAs.

${ }^{7}$ Glaeser, Resseger, and Tobio (2008) measure human capital with a similar earnings prediction as mine, but their focus is inequality of human capital at the city level.
} 
measure. $^{8}$

\subsection{Results from U.S. state skill accounting exercise}

I find evidence of regression toward the mean of state skills from one generation to the next. This works through intergenerational transmission of skills: states with the highestand lowest-skilled parents tend to have children with skills closer to the national mean level of skills. Across states, migration does not send skills disproportionately to states with higher or lower skills in the previous generation.

Table B.4 in Appendix B lists estimates for all states. Table 2 displays descriptive statistics of them. Differences between the distributions of $K_{j g}$ and $K_{j g} \Lambda_{j g}$ capture the effects on state skills of native skill retention. Differences between the distributions of $K_{j g} \Lambda_{j g}$ and $S_{j g}$ capture the effects on state skills of in-migration. The fact that $\Lambda_{j g}$ is less than one for all states is a dramatic effect of the relationship between individual skill and migration behavior. More-skilled people are more mobile, so out-migrants are more skilled than stayers for all states. The fact that $M_{j g}$ is greater than one for all states shows the same relationship from the opposite perspective. Table 3 lists correlations between parameters to show the average relationships between skill measures of states.

The slope coefficient from a regression of $\ln \left(S_{j g}\right)$ on $\ln \left(S_{j g-1}\right)$ is a measure of generationto-generation persistence in state skills. Similarly, the relationship between parent skills $\left(S_{j g-1}\right)$ and child skills $\left(K_{j g}\right)$ illustrates the role of intergenerational transmission in determining persistence of state skills. Finally, the relationships between previous state skills and measures of skilled migration $\left(\Lambda_{j g}\right.$ and $\left.M_{j g}\right)$ illustrate the corresponding role of migration.

Table 4 describes these relationships. ${ }^{9}$ Each column represents a separate regression

\footnotetext{
${ }^{8}$ The ratio of high-skilled to low-skilled populations is clearly related to other measures. In the 2000 Census, the correlation between percent of adults with a college degree and my measure $\ln \left(S_{j g}\right)$ at the state level is 0.94 . At the commuting zone level, the analogous correlation is 0.64 .

${ }^{9}$ Since some of the dependent variables in Table 4 are functions of the others, it is possible to calculate some of these coefficients from the others. In particular, the slope coefficient in Column 1 is the sum of slopes in Columns 2 and 3. Also, the slope coefficient in Column 3 is the sum of slopes in Columns 4 and 5. Rounding obscures the equalities.
} 
where observations are states. ${ }^{10}$ Column 1 includes results from regressing a state's skill ratio on the skill ratio of the previous generation in the state. State skill ratios are persistent across generations, although there is some regression toward the mean in skill. The slope coefficient of the regression of log skill ratio on previous generation log skill ratio at the state level is 0.65 with a standard error of 0.14 . The $R^{2}$ is 0.32 , implying that factors other than the previous generation's skills have a large role in determining a state's skill level. ${ }^{11}$

The dependent variable in Column 2 of Table 4 is the log state skill ratio of natives of the state. This is equivalent to the skill ratio of adults if intergenerational transmission were the only mechanism affecting the geographic skill distribution. I regress this variable on the natural logarithm of the previous generation's state skill ratio. The slope coefficient of 0.66 is close to the overall slope of 0.65 , which implies that intergenerational transmission dominates the relationship between state skills from one generation to the next. ${ }^{12}$

This relationship of skills across generations at the location level can be compared to intergenerational transmission of skills within the family. Solon (1999) surveys the literature on the intergenerational transmission of earnings. The consensus estimate of the elasticity of child earnings with respect to parent earnings lies between 0.3 and 0.5 in

\footnotetext{
${ }^{10}$ Since the variables entering the regressions are themselves estimates of population parameters, there is a potential for errors-in-variables bias in OLS estimates. For this reason, I report results in Table 4 that account for sampling error in the dependent and independent variables. Deaton (1985) describes the method. The idea is as follows: Let $Y^{*}$ and $X^{*}$ be dependent and independent variables, respectively, with no sampling error. Let $Y$ and $X$ be the data. Let $\sigma$ be the covariance of the additive sampling errors in $Y$ and $X$ and $\Sigma$ be the covariance matrix of sampling errors in $X$. Additive sampling error induces additive errors in moment matrices that enter OLS, so $E\left(X^{\prime} X\right)=E\left(X^{*^{\prime}} X^{*}\right)+\Sigma$ and $E\left(X^{\prime} Y\right)=E\left(X^{*^{\prime}} Y^{*}\right)+\sigma$. I calculate estimates of $\Sigma$ and $\sigma$, which are functions of skill proportions and Census sample sizes. Then, $\left(X^{\prime} X-N \hat{\Sigma}\right)^{-1}\left(X^{\prime} Y-N \hat{\sigma}\right)$, where $N$ is the number of observations, is a consistent estimate of the vector of slope coefficients. In practice, the results are very similar to those from OLS regressions.

${ }^{11}$ An alternative specification takes the state skill measure to be the state average of log earnings predictions, rather than the ratio of skill category populations. Regressing the 2000 state average of log earnings predictions (assigned to adult residence states) on the 1980 state average of log earnings predictions (assigned to adult residence states) yields a slope coefficient estimate of 0.623 with a standard error of 0.126 . The $R^{2}$ is 0.334 .

${ }^{12}$ Regressing the 2000 state average of log earnings predictions (assigned to birth states) on the 1980 state average of log earnings predictions (assigned to adult residence states) yields a slope coefficient estimate of 0.632 with a standard error of 0.111 . The $R^{2}$ is 0.399 .
} 
the U.S. (page 1780). State skill ratio persistence appears to be higher than family-level intergenerational earnings persistence.

Studies of the relationship between parents' schooling and children's schooling are also consistent with family-level persistence and some mean reversion. In cross sections, children's schooling tends to increase less than one-for-one with parents' schooling. This is the case in Behrman and Rosenzweig (2002) with U.S. data and in Black, Devereux, and Salvanes (2005) with Norwegian data. ${ }^{13}$

The rest of Table 4 describes the relationship between state skills in the previous generation and selective migration. Note that migration is common enough in the U.S. to have a potentially large effect on the distribution of skills across states in one generation. In the 2000 Census sample of workers, 38 percent live in their 30s in states that are not their birth states.

The regression in Column 3 of Table 4 has as its dependent variable the factor describing the total migration effect on the state skill ratio $\left(\Lambda_{j g} M_{j g}\right)$. The near-zero slope coefficient implies that migration does not affect skills differently in states with high- and low-skilled previous generations. ${ }^{14}$ Columns 4 and 5 of Table 4 decompose the effect of migration on state skills into parts due to native retention $\left(\Lambda_{j g}\right)$ and in-migration $\left(M_{j g}\right)$. The relationship between previous generation skills and the total migration effect on state skills is small, because neither native retention nor in-migration of skills has a strong relationship with previous skills.

\footnotetext{
${ }^{13}$ Much of the recent literature on this topic attempts to decompose the cross-sectional correlation into parts due to genetic and environmental factors. Behrman and Rosenzweig's (2002) identification strategy compares outcomes of twins. Black, Devereux, and Salvanes (2005) exploit parental schooling variation due to compulsory schooling law changes. Björklund, Lindahl, and Plug (2006) and Sacerdote (2007) compare adopted children with non-adopted children. Björklund, Lindahl, and Plug (2006) use Swedish register data. Sacerdote (2007) collected his own data that describes children adopted from Korea by U.S. families through Holt International Children's Services.

${ }^{14}$ Results using state averages of log earnings predictions are similar to these results using the population ratio measure. Let $\bar{y}_{r}$ be the average earnings prediction of residents in a state. Let $b$ denote natives, $l$ denote leavers, and $m$ denote in-migrants. Their populations are $N_{b}, N_{l}$, and $N_{m}$, respectively. Then, $\bar{y}_{r}=$ $\frac{N_{b} \bar{y}_{b}-N_{l} \bar{y}_{l}+N_{m} \bar{y}_{m}}{N_{b}-N_{l}+N_{m}}=\bar{y}_{b}\left(\frac{N_{b}-N_{l}\left(\bar{y}_{l} / \bar{y}_{b}\right)+N_{m}\left(\bar{y}_{m} / \bar{y}_{b}\right)}{N_{b}-N_{l}+N_{m}}\right) \equiv \overline{y_{b}} \tilde{M}$, where $\tilde{M}$ is a multiplicative factor that describes how migration affects the average earning prediction in the state. Regressing $\tilde{M}$ on the 1980 state average of log earnings predictions (assigned to adult residence states) yields a slope coefficient estimate of -0.001 with a standard error of 0.016 . The $R^{2}$ is 0.0002 . So, migration does not affect the average skill measure differentially in states with high and low skill in the previous generation.
} 


\section{A model of the geographic distribution of human capital over time}

\subsection{Introduction of the framework}

A weakness of the analysis so far is that states are poor proxies of local labor markets, because states are heterogeneous and their boundaries cut across unified economic areas. This section describes a model of the geographic distribution of human capital that will be useful in addressing this weakness. The primary purpose of the model is to provide a framework for estimating skill levels of local labor markets that are smaller than states. It does so by providing a link from individual skill acquisition and migration behavior to the geographic distribution of human capital. A secondary purpose of the model is to indicate what kinds of labor market characteristics affect local skill levels.

The framework is an over-lapping generations model. There are two decisions that each member of each generation makes. The first is which skill level to acquire as a child. Skill is indexed by $s$ and takes on values $H$ and $L$ for high- and low-skilled individuals, respectively. The second decision is where to live as an adult. Individuals can choose to stay in their origin location or to move to any of the other locations in the economy.

Figure 1 illustrates the timing of events in the model. People are born and grow up in a labor market. In their birthplace, they decide whether to become high- or low-skilled workers. They make a migration decision as adults, choosing to stay in their origin or move to any other labor market. After the migration decision, they work and have children in their chosen location and die. Members of the new generation then make the skill investment and migration decisions and have children and work in their chosen location. Each labor market clears in each period (generation) so that the relative supply of high- to low-skilled workers in each labor market equals the relative demand for high- to low-skilled workers there. 


\subsection{Decomposition of local relative supply of skills}

The local supply of skills is the aggregation of skill acquisition and migration decisions. I describe skill acquisition and then migration decisions. I then aggregate them to represent local relative skill supply.

Let $U_{s i j}$ be the net benefit to individual $i$ growing up in location $j$ of having skill level $s$. This is a function of expected benefits and costs to investing in skills. Individual $i$ chooses to invest in high skills if $U_{H i j}-U_{L i j}>0$ and chooses low skills otherwise. Let $\operatorname{Par}_{H i}$ be an indicator for child $i$ having high-skilled parents and $z_{j}$ be a vector of characteristics of $i$ 's origin location $j$. The following equation represents net benefits of high relative to low skill acquisition for individual $i$ :

$$
U_{H i j}-U_{L i j}=\alpha_{1}+\alpha_{2} \operatorname{Par}_{H i}+\alpha_{3} z_{j}+\alpha_{4} \operatorname{Par}_{H i} z_{j}-\epsilon_{i j} .
$$

Parents' skills affect the costs of acquiring skill, as do location characteristics in $z_{j}$, such as proximity to college. Assume $\epsilon_{i j} \sim N(0,1)$. Then, the following formulas measure skill acquisition rates:

$$
\begin{aligned}
P_{H L j} & =\Phi\left(\alpha_{1}+\alpha_{3} z_{j}\right) \\
P_{H H j} & =\Phi\left(\alpha_{1}+\alpha_{2}+\left(\alpha_{3}+\alpha_{4}\right) z_{j}\right) .
\end{aligned}
$$

$\Phi(\cdot)$ is the standard normal cumulative distribution function. $P_{H L j}$ is an estimate of the probability that a child growing up with low-skilled parents in a location with characteristics $z_{j}$ will be high-skilled. $P_{H H j}$ is the probability that a child growing up with highskilled parents in a location with characteristics $z_{j}$ will be high-skilled.

The next decision individuals make is where to live when adults. ${ }^{15}$ Let $s(i)$ be a func-

\footnotetext{
${ }^{15}$ The model at present does not allow the skill acquisition and migration decisions to interact. The primary reason is simplicity, both in model exposition and estimation. If children acquire skills because they are anticipating their use of those skills in some labor market other than their origin, then this method will mistakenly identify location characteristics as inducing migration instead of the acquisition of skills. Although the method may mistake the reasons for skill acquisition and migration behavior, the assumed lack of interaction between these two choices does not compromise the predictions of skill stocks and flows
} 
tion that gives the skill level of individual $i$ and $b(i)$ be a function that gives the birthplace of individual $i$. The utility that individual $i$ attains from residing in location $k$ in generation $g$ is

$$
V_{i k g}=\gamma \ln \bar{W}_{s(i) k g}+\beta_{s(i) g} z_{b(i) k g}+\xi_{i k g}
$$

where $\bar{W}_{s(i) k g}$ is the location $k$ average wage among residents with skill level $s$ and $z_{b(i) k g}$ is a vector of location characteristics. This vector includes interactions between origin and destination characteristics, so individuals from different origins attach different values to destination characteristics. For example, distance between origin and a potential destination is allowed to enter $V_{i k g}$.

Note also the treatment of wages. Average wages enter the utility function, which could be justified by assuming individuals have imperfect information about wages they will be able to earn in any given location. This is unrealistic but perhaps not extreme in this context, where my focus is on estimating average preferences and behavior. Moreover, I constrain the marginal utility of labor earnings $(\gamma)$ to be the same for both skill levels.

The residual $\xi_{i k g}$ is distributed extreme value independently and identically across $i, k$, and $g$. This distribution of the residuals implies that the probability of utility-maximizing individual $i$ locating in $k$ is (letting $i$ 's origin be $j$ and $i^{\prime}$ s generation be $g$ )

$$
P_{i j k g}=\frac{\exp \left(\gamma \ln \bar{W}_{s(i) k g}+\beta_{s(i) g} z_{j k g}\right)}{\sum_{l} \exp \left(\gamma \ln \bar{W}_{s(i) l g}+\beta_{s(i) g} z_{j l g}\right)} .
$$

See McFadden (1974).

I now aggregate the skill acquisition and migration decisions in order to characterize the relative supply of skills to a labor market. I take notation from the accounting exercise above, so $S_{j g}=A_{H j g} / A_{L j g}$ is the relative supply of high- to low-skilled adults of generation $g$ to location $j$, and $P_{s j k g}$ is the probability that an individual with skill $s$ chooses to migrate from location $j$ to location $k$. I add here that an expression for the number of across labor markets. 
in-migrants to $j$ with skill level $s$ is \#InMig ${ }_{s j g}=\sum_{k \neq j} C_{s k g} P_{s k j g}$. Then, following Equation 1 , the location $j$ relative supply of skills can be expressed as

$$
S_{j g}=\frac{C_{H j g} P_{H j j g}\left(\frac{\sum_{k} C_{H k g} P_{H k j g}}{C_{H j g} P_{H j j g}}\right)}{C_{L j g} P_{L j j g}\left(\frac{\sum_{k} C_{L k g} P_{L k j g}}{C_{L j g} P_{L j j g}}\right)} .
$$

I can decompose this supply into the intergenerational transfer mechanism and migration. The former is the mechanism that maps local parents' skills into local children's skills. Define the skill transmission function to be

$$
\begin{aligned}
K_{j}\left(\frac{A_{H j g-1}}{A_{L j g-1}}\right)=\frac{\left(A_{H j g-1} / A_{L j g-1}\right) P_{H H j}+P_{H L j}}{\left(1-P_{H L j}\right)+\left(A_{H j g-1} / A_{L j g-1}\right)\left(1-P_{H H j}\right)} & =\frac{A_{H j g-1} P_{H H j}+A_{L j g-1} P_{H L j}}{A_{L j g-1}\left(1-P_{H L j}\right)+A_{H j g-1}\left(1-P_{H H j}\right)}=\frac{C_{H j g}}{C_{L j g}} .
\end{aligned}
$$

Defining $K_{j}$ as a function rather than a multiplier, as in the accounting exercise, allows a more explicit treatment of intergenerational transmission, which is possible with the NELS:88. Further define $\Lambda_{j g}=P_{H j j g} / P_{L j j g}$ to describe the effect of retention of natives on the local skill distribution. Finally, define

$$
M_{j g}=\left(\frac{\sum_{k} C_{H k g} P_{H k j g}}{C_{H j g} P_{H j j g}}\right) /\left(\frac{\sum_{k} C_{L k g} P_{L k j g}}{C_{L j g} P_{L j j g}}\right)
$$

to describe the effect of in-migration on the local skill distribution. $M_{j g}$ is the growth of high skills relative to the growth of low skills through in-migration.

Plugging these definitions into Equation 5, the evolution of relative skills in location $j$ follows

$$
S_{j g}=K_{j}\left(S_{j g-1}\right) \times \Lambda_{j g} \times M_{j g}
$$

I will estimate each element of this equation in order to assess how the intergenerational transmission of skills and migration contribute to the geographic distribution of skill. 


\subsection{Equilibrium in local labor markets}

Each labor market of the model clears in every period (generation). Equilibrium is reached when the relative supply of skills in each labor market equals the relative demand for skills. The relative supply of skills to labor market $j$ is, plugging the location choice probabilities of Equation 4 into the supply Equation 1,

$$
\begin{aligned}
S_{j g}=\frac{A_{H j g}}{A_{L j g}} & =\frac{\# \operatorname{Htay}_{H j g}+\# \operatorname{InMig}_{H j g}}{\text { \#Stay }}{ }_{L j g}+\# \operatorname{InMig} \operatorname{lig}_{L j g} \\
& =\frac{\sum_{k} C_{H k g} P_{H k j g}}{\sum_{k} C_{L k g} P_{L k j g}} \\
& =\frac{\sum_{k} C_{H k g}\left(\frac{\exp \left(\gamma \ln \bar{W}_{H j g}+\beta_{H g} z_{k j g}\right)}{\sum_{l} \exp \left(\gamma \ln \bar{W}_{H l g}+\beta_{H g} z_{k l g}\right)}\right)}{\sum_{k} C_{L k g}\left(\frac{\exp \left(\gamma \ln \bar{W}_{L j g}+\beta_{L g} z_{k j g}\right)}{\sum_{l} \exp \left(\gamma \ln W_{L l g}+\beta_{L g} z_{k l g}\right)}\right)} \\
& =\frac{\exp \left(\gamma \ln \bar{W}_{H j g}\right) \sum_{k} C_{H k g}\left(\frac{\exp \left(\beta_{H g} z_{k j g}\right)}{\sum_{l} \exp \left(\gamma \ln \bar{W}_{H l g}+\beta_{H g} z_{k l g}\right)}\right)}{\exp \left(\gamma \ln \bar{W}_{L j g}\right) \sum_{k} C_{L k g}\left(\frac{\exp \left(\beta_{L g} z_{k j g}\right)}{\sum_{l} \exp \left(\gamma \ln \bar{W}_{L l g}+\beta_{L g} z_{k l g}\right)}\right)}
\end{aligned}
$$

Let $s_{j g} \equiv \ln \left(S_{j g}\right)$ and $w_{j g} \equiv \ln \left(\bar{W}_{H j g} / \bar{W}_{L j g}\right)$. Then, the relative supply of skills to location $j$ is

$$
s_{j g}=\gamma w_{j g}+\Psi_{j g}
$$

where $\Psi_{j g}$ is a function of attributes of location $j$ at time $g$ relative to other locations.

Let $D_{j g}$ be the local relative demand for high- and low-skilled individuals, and $d_{j g} \equiv$ $\ln \left(D_{j g}\right)$. The following equation describes the local relative demand for skills:

$$
d_{j g}=-\sigma w_{j g}+e_{j g}
$$

$\gamma$ and $\sigma$ are positive parameters that represent elasticities with respect to the local relative wage. ${ }^{16}$

In equilibrium, each local labor market must clear so that $s_{j g}=d_{j g}$. This implies the

\footnotetext{
${ }^{16}$ This representation of local relative labor supply and demand draws upon Bound, Groen, Kezdi, and Turner (2004). The labor demand function is appropriate if local production has constant elasticity of substitution $(-\sigma)$ between high- and low-skilled labor.
} 
following:

$$
d_{j g}=s_{j g}=\frac{\gamma}{\gamma+\sigma} e_{j g}+\frac{\sigma}{\gamma+\sigma} \Psi_{j g}
$$

The local skill premium is

$$
w_{j g}=\frac{e_{j g}-\Psi_{j g}}{\gamma+\sigma}
$$

Relative wages tend to be higher in labor markets with strong relative demand for skills $\left(e_{j g}\right)$ and lower in labor markets with amenities valued more by higher- than lower-skilled workers $\left(\Psi_{j g}\right)$.

The rate of growth in local relative skills that comes through migration is given by the term $\Lambda_{j g} \times M_{j g}$ in Equation 7. ${ }^{17}$ In equilibrium, the following holds:

$$
\begin{aligned}
\ln \left(\Lambda_{j g} \times M_{j g}\right) & =s_{j g}-\ln \left[K_{j}\left(S_{j g-1}\right)\right] \\
& =\frac{\gamma}{\gamma+\sigma} e_{j g}+\frac{\sigma}{\gamma+\sigma} \Psi_{j g}-\ln \left[K_{j}\left(S_{j g-1}\right)\right]
\end{aligned}
$$

This equation makes clear that relative skill flows from migration depend upon current location characteristics (relative to other locations) that affect relative demand and supply, previous generations' location decisions, and the local intergenerational transmission of human capital. ${ }^{18}$

${ }^{17}$ To see this, note that

$$
\begin{aligned}
\Lambda_{j g} \times M_{j g} & =\frac{P_{H j j g}\left(\frac{\sum_{k} C_{H k g} P_{H k j g}}{C_{H j g} P_{H j g}}\right)}{P_{L j j g}\left(\frac{\sum_{k} C_{L k g} P_{L k j g}}{C_{L j g} P_{L j j g}}\right)} \\
& =\frac{\frac{\sum_{k} C_{H k g} P_{H k j g}}{C_{H j g}}}{\frac{\sum_{k} C_{L k g} P_{L k j g}}{C_{L j g}}} \\
& =\frac{\sum_{k} C_{H k g} P_{H k j g} / \sum_{k} C_{L k g} P_{L k j g}}{C_{H j g} / C_{L j g}}
\end{aligned}
$$

${ }^{18} \mathrm{An}$ important feature of the model to keep in mind is that quantities are always ratios. As a result, local characteristics that affect high- and low-skilled individuals in the same way do not affect the equilibrium relative skill level. For example, cost of living that deflates all nominal wages in a city by the same proportion should not have an effect on the local relative supply of skills. Amenities that are valued the same between high- and low-skilled individuals should not affect the relative supply of skills. Amenities that are normal goods, however, will tend to draw the higher skilled (with higher incomes) at higher rates. Cost of living and amenities in this model do affect total population flows into and out of locations, but my focus will be on relative flows of high- and low-skilled populations. 
I describe data in Section 5 below. I then describe in Section 6.1 how I use the data to estimate variables of the model for local labor markets $j$ and two generations. Relationships among measured variables $S_{j g-1}, K_{j g}$, and $S_{j g}$ indicate the degree to which intergenerational transmission of skill and migration affect local human capital. Equation 11 is a reduced form equation I will then estimate in order to identify characteristics of labor markets that draw skills through migration.

\section{Data description}

The location definition in this study approximates a labor market, which I consider to be the smallest geographic space where most residents work and most workers reside. I use the commuting zone (CZ) as the location definition. Tolbert and Sizer (1996) describe the identification of CZs using journey-to-work data from the 1990 Census. Each CZ is a collection of counties (or single county) that share particularly strong commuting links. The CZ definition has the added feature of encompassing both rural and urban areas. ${ }^{19}$

There are $741 \mathrm{CZs}$ in the U.S. 604 of them are entirely contained by a single state, 129 of them by two states, and 8 of them by three states (eg, Washington, D.C.). CZ populations in 2000 range from 1,193 (Murdo, SD) to 16,393,360 (Los Angeles, CA). 258 CZs contain a metropolitan statistical area.

I calculate some average characteristics of CZs with the U.S. Census. I use the 1990 and 20005 percent samples available through IPUMS. These characteristics include average wages, percent with college degrees, and percent employment in manufacturing. The smallest identifiable area in the Census is the public use microdata area (PUMA), which is a Census-defined place with population no less than 100,000. This definition does not allow perfect matching of boundaries for all CZs. The method used to convert PUMA averages to $C Z$ averages involves assigning PUMA characteristics to a $C Z$ based on the population weight of the PUMA in the CZ. The data appendix includes a more detailed

\footnotetext{
${ }^{19}$ This is the same location definition used in Autor and Dorn (2008) to study the interactions of different types of workers within labor markets.
} 
description of the method.

Additional CZ characteristics come from various sources. I aggregate $\mathrm{CZ}$ population from county population files available through IPUMS. Region and urban status come directly from Tolbert and Sizer (1996). I calculate average climate characteristics (such as average temperatures and snowfall) using data from the National Climatic Data Center. I characterize CZs as being coastal if at least one of the counties making up the $\mathrm{CZ}$ has an ocean coastal property. The distance between two CZs is the great circle distance between their latitude and longitude coordinates, in kilometers.

I use state higher education appropriations and public college tuition data from Fortin (2006). From the data Fortin make available, I calculate higher education appropriations per full-time equivalent student and public tuition per public college student for each state. The higher education subsidy variable I use in some specifications is the appropriations variable divided by the tuition variable.

I also calculate college enrollment for each CZ. I acquire college enrollment in each county from the Integrated Postsecondary Education Data System (IPEDS) at the National Center for Education Statistics (NCES) and sum over counties to get CZ enrollments. The enrollment measure is the full-time equivalent number of undergraduate students at twoyear and four-year colleges.

I use state wage and capital tax data from Daniel Feenberg at the National Bureau of Economic Research (NBER). The variables I use are the highest marginal tax rates that people face in each state. These rates combine Federal and state taxes. Information about the program used to calculate tax rates (TAXSIM) is available in Feenberg and Coutts (1993).

CZs sometimes consist of counties in more than one state. For state-level variables (higher education appropriations, tuition, and tax rates), I assign to each CZ the characteristics of the state with the larger share of $\mathrm{CZ}$ population.

Table 5 displays descriptive statistics for the $741 \mathrm{CZs}$. The range of percent residents with college degrees from Table 1 is repeated. People choosing residential location have a 
set of choices that is very diverse along many dimensions, which helps identify characteristics that contribute to the skill distribution. The range of average wages, temperatures, industry structures, populations, tax policies, and subsidy rates for public higher education are all quite large.

To investigate both the intergenerational transmission of skill and early migration decisions, I use the National Education Longitudinal Study of 1988 (NELS:88). Several features of the NELS:88 address the weaknesses of using the Census for the present purposes. First, the restricted-use version of the NELS:88 has zip code data that identify the $\mathrm{CZ}$ of residence for each respondent, both in 8 th grade and at age 26. Second, the NELS:88 includes more informative data on individual skills and family background, most notably test scores and parent's education. Third, the NELS:88 has information about the parents of each respondent, allowing investigation of the intergenerational transmission of skill at the family level. Fourth, the NELS:88 identifies location of respondents at 8 th grade, which is more likely to approximate the location of skill acquisition than the birth state in the Census data.

NELS:88 data collection began with a representative sample of students in the eighth grade of U.S. schools in 1988. Follow-up surveys were completed in 1990, 1992, 1994, and 2000. In the final follow-up, students were around 26 years old and mostly out of school. They were making early family formation and labor market decisions, including geographic location choices. Labor market information includes annual earnings and whether full-time, in addition to occupation and industry.

Figure 2 implies that a weakness of the NELS:88 data for my purposes is the relatively young age at final follow-up. Figure 2 plots two types of average migration rates from the 2000 Census by age. The series refer to migration defined as changing houses and changing states between 1999 and 2000. One-year migration rates peak just before the age of the final location information from NELS:88 respondents. The model above includes a single location decision for each agent, which may not be approximated well by the relatively early location decisions in these data. 
Table 6 provides summary statistics for the NELS:88 sample I use. There are approximately 11,080 respondents with non-missing location information in 8th grade and the 2000 follow-up survey. ${ }^{20}$ For this table and all estimation with the NELS:88, I apply sample weights that make the NELS:88 sample representative of 8 th grade students in U.S. schools in 1988. Table 6 also shows that migration out of one's origin CZ is common. About 35 percent of respondents lived at age 26 in a $C Z$ other than their 8th grade $C Z$.

Migration behavior varies substantially across skill levels and family backgrounds. Table 6 shows that college graduation, the test score index, parent's education, parent's income, and early labor market earnings are all higher for those who had migrated away from their 8th grade labor market. The test score index is defined such that a 0.1 increase in the index represents a change in math and verbal scores on an 8 th grade test that predict a 0.1 increase in log earnings. ${ }^{21}$

\section{Estimation of the model and results}

\subsection{Estimation of model parameters}

The major steps in estimation are the following: I use Census data to estimate skill ratios of a parent generation in each $\mathrm{CZ}$ (that is, $S_{j g-1}$ ). I then measure intergenerational skill transmission and migration behavior at the individual level using the NELS:88. With $S_{j g-1}$ and information about intergenerational transmission for each CZ, I estimate the native child skill ratios $K_{j g}$. I then estimate migration propensities to and from each $\mathrm{CZ}$ in the NELS:88 to infer post-migration skill ratios of the second generation $\left(S_{j g}\right)$.

In estimation, I depart from the model in one significant way. When defining skill categories of parents and children, I allow there to be four skill levels instead of two. I use

\footnotetext{
${ }^{20}$ Following requirements for the use of restricted-access NELS:88 data, I round all unweighted sample sizes describing these data to the nearest ten. I follow this procedure throughout this paper.

${ }^{21}$ The index ranges from 9.950 to 10.145 . The index at mean eighth grade test scores is 10.030 . The index at one standard deviation higher on verbal and math scores is 10.052, representing a gain in predicted annual earnings of about 2 percent.
} 
four skill levels in order to have more of a distinction between high- and low-skilled individuals than splitting the sample in half would yield, while using all of the data available.

The first step in estimating the model is measuring, for each U.S. labor market, the skill distribution of the generation of NELS:88 parents. I take this cohort to be workers in the 5 percent 1990 Census who were ages 34 through 56 . With full-time workers from this sample, I estimate Equation 3 by OLS. I use coefficients from this regression to predict log weekly labor earnings for all workers, setting the state indicator for New York equal to one and all others to zero. High-skilled people make up the highest quartile of the national predicted earnings distribution, and low-skilled people make up the lowest quartile. The estimate of $S_{j g-1}$, the skill ratio in labor market $j$ among the parent generation, is the ratio of high-skilled to low-skilled populations in $\mathrm{CZ} j$.

The next steps in estimating the model are estimating the intergenerational transmission of skill and location choice models with the NELS:88. I categorize NELS:88 respondents into skill categories that correspond with quartiles of a predicted earnings distribution. The form of the regressions is similar to the one used with the Census, although earnings predictions with the NELS:88 use data on test scores and parents' education but not occupation. The other difference is that I measure annual earnings in the NELS:88 rather than weekly earnings. ${ }^{22}$

I also categorize NELS:88 parents into skill groups according to predicted earnings. Characteristics of NELS:88 parents are somewhat limited; in particular, parents report household earnings without assigning them to individual earners. So, I use the Panel Study of Income Dynamics (PSID) to form a skill measure for the NELS:88 parents. I regress a permanent measure of log annual earnings of PSID respondents on sex, race, education, and occupation. ${ }^{23}$ I use the estimated coefficients to predict permanent log annual earnings of NELS:88 parents. The parent skill measure is the average of a NELS:88 students' parent earnings predictions. Respondents with a parent skill measure in the

\footnotetext{
${ }^{22}$ I do not use earnings from periods before a respondent finished schooling. Some respondents were in school at the time of the final survey. I include them in the sample used to estimate skill acquisition and migration behavior. Appendix A describes this issue in more detail.

${ }^{23}$ I give more detail about the PSID earnings prediction in Appendix A.
} 
highest quartile have high-skilled parents, and respondents with a parent skill measure in the lowest quartile have low-skilled parents.

I then estimate separate probit models for students attaining each skill level, as functions of parents' skill categories and characteristics of the origin CZ. The results from these probit models are in Table B.1 in Appendix B. As expected, the skill level of parents is a clear predictor of child skill. Some location characteristics are correlated with the skill acquisition of local youth. These specifications include many location characteristics, making interpretation of marginal effects difficult. For example, the coefficient on log college subsidy needs to be interpreted as the partial effect of subsidies controlling for variables including college enrollment per capita, wage taxes, local wages, and percent residents with college degrees. The purpose of including so many variables is to capture much of the variation across labor markets in the intergenerational transmission of skills.

One of these probit models estimates the probability that a high-skilled parent in $\mathrm{CZ} j$ will have a high-skilled child. In model language, this is an estimate of $P_{H H j}$. The probit models also estimate the probabilities of intergenerational skill transfer between all pairs of parent and child skill types in all CZs. Using these, I calculate the model parameter $K_{j}\left(S_{j g-1}\right)$ for each labor market $j$, using the estimated $S_{j g-1}$ from the Census and a fourskill analogue of Equation $6 .{ }^{24}$

Next, I estimate migration probabilities using a separate logit model for each skill category, where the choice is among CZs of residence. The form of the logits that I estimate

\footnotetext{
${ }^{24}$ More specifically, let $M H$ and $M L$ denote medium-high and medium-low skills, respectively. These refer to the second-highest and third-highest quartiles in the predicted earnings index. From the 1990 Census, I estimate local adult populations $A_{H j g-1}, A_{M H j g-1}, A_{M L j g-1}$, and $A_{L j g-1}$. Then, estimates of the next generation's child skill populations are

$$
\begin{aligned}
C_{H j g} & =A_{H j g-1} P_{H H j}+A_{M H j g-1} P_{H M H j}+A_{M L j g-1} P_{H M L j}+A_{L j g-1} P_{H L j} \\
C_{L j g} & =A_{H j g-1} P_{L H j}+A_{M H j g-1} P_{L M H j}+A_{M L j g-1} P_{L M L j}+A_{L j g-1} P_{L L j}
\end{aligned}
$$

and $K_{j}\left(S_{j g-1}\right)=C_{H j g} / C_{L j g}$.
} 
uses the following specification for the utility to individual $i$ living in $\mathrm{CZ} k$ :

$$
\begin{aligned}
V_{i k}=\gamma_{s(i)} \ln \bar{W}_{s(i) k}+ & \beta_{s(i) 1} \text { Home }_{i k}+\beta_{s(i) 2} \text { Distance }_{i k}+\beta_{s(i) 3} \text { Distance }_{i k}^{2} \\
& +\beta_{s(i) 4} z_{k}+\beta_{s(i) 5} \text { Home }_{i k} z_{k}+\beta_{s(i) 6} \operatorname{Rural}_{b(i)} z_{k}+\beta_{s(i) 7} z_{k} z_{b(i)}+\xi_{i k},
\end{aligned}
$$

where Home $e_{i k}$ is an indicator for $k$ being $i^{\prime}$ s origin CZ, Distance ${ }_{i k}$ is the distance in kilometers between $k$ and $i$ 's origin CZ, $\operatorname{Rural}_{b(i)}$ is an indicator for $i$ 's origin CZ being rural, $z_{k}$ is a vector of destination characteristics, and $z_{b(i)}$ is a vector of origin characteristics. I estimate $\bar{W}_{s(i) k}$ for each destination as the average wage of local workers in skill category $s$. I do not constrain $\gamma_{s(i)}$ to be the same across skill levels as the model assumes.

Tables B.2 and B.3 display parameters from logit models that estimate location choices of NELS:88 respondents. Since destination choices depend on both supply and demand factors, the coefficient on average wages can be positive or negative. One would not expect this estimate necessarily to be consistent for the slope of the relative supply curve.

The coefficients on Home $i k$ show that people of both skill levels are much more likely to stay in their labor market of origin than move to another. There is also a significant utility reduction associated with distance from origin, and this is quite consistent across skill levels.

Conditional on other location characteristics, the Northeast is the least attractive destination for both skill levels, and the West is the most attractive destination for high-skilled individuals. The percent college at origin tends to encourage people to leave, although the percent college of non-home destinations tends to be a positive amenity (or it is correlated with some other positive amenity in the residual). This is most clearly the case with higher-skilled individuals. ${ }^{25}$

In model language, the logit models yield estimates of $P_{H j k g}$ and $P_{L j k g}$ for all combinations of labor markets $j$ and $k$, including $j=k$. With these, I calculate $\Lambda_{j g}=P_{H j j g} / P_{L j j g}$

\footnotetext{
${ }^{25}$ Among college attenders who ended up in high college-share CZs (with more than 30 percent college graduates), 57 percent lived at age 26 where they went to college. Across all CZs, 61 percent of college attenders lived at age 26 in the $\mathrm{CZ}$ where they went to college.
} 
and $M_{j g}=\left(\frac{\sum_{k} C_{H k g} P_{H k j g}}{C_{H j g} P_{H j j g}}\right) /\left(\frac{\sum_{k} C_{L k g} P_{L k j g}}{C_{L j g} P_{L j j g}}\right)$ for each $j$, where $C_{H j g}$ and $C_{L j g}$ come from the procedure used to calculate $K_{j}\left(S_{j g-1}\right)$ (see Footnote 24$)$. The final parameter to estimate is $S_{j g}=K_{j}\left(S_{j g-1}\right) \Lambda_{j g} M_{j g}$ for each $j$.

NELS:88 8th graders lived in only approximately 310 of the $741 \mathrm{CZs}$, so I do not observe skill acquisition in or migration from many of the CZs in the U.S. ${ }^{26}$ I can still predict skills for all $741 \mathrm{CZs}$, since the model specifies CZ skills simply as functions of $\mathrm{CZ}$ characteristics. However, predicting local skills for CZs that I do not observe in the data probably generates significant additional error in estimates describing these CZs. For this reason, I perform the analysis below using only the approximately $310 \mathrm{CZs}$ where NELS:88 8th graders lived (that is, those in the support of the data). ${ }^{27}$

As a robustness check, I estimate the model with the NELS:88 using states instead of CZs as locations. If the model estimation procedure is reliable, then this exercise will replicate findings from the accounting exercise that uses Census data alone. For the most part, this is the case. I describe the results in Appendix C. Overall, model estimation with the NELS:88 has enough precision to replicate findings in the Census, and this adds credibility to the procedure for understanding the geographic distribution of human capital.

\footnotetext{
${ }^{26}$ Following requirements for the use of restricted-access NELS:88 data, I round the number of CZs where NELS:88 respondents lived to the nearest ten.

${ }^{27}$ When I include in the analysis predictions for all $741 \mathrm{CZs}$, outliers handicapped inference about relationships at the CZ level. Evidently, the problem is that estimates for CZs not observed in the NELS:88 sample - but for which I generate model estimates - include too much estimation error. One category of CZs that appears to have relatively poor fit is small college towns. The NELS:88 sample includes some small CZs with relatively high supplies of college services, but they do not cover the highest part of the college supply distribution. In this part of the distribution, the model estimates implausibly high skill gains.

I tested the sensitivity of results to changes in the CZ sample composition. Dropping CZs with fewer than 20 NELS:88 respondents did not make much difference. Increasing that threshold to 30 started to change results by dropping small CZs disproportionately. I also used probit models to predict the probability of inclusion into the NELS:88 base year sample with flexible functions of CZ characteristics. Keeping CZs in the NELS: 88 sample plus those with relatively high inclusion probabilities yield similar results to those presented here. When I include omitted CZs with NELS:88 inclusion probabilities as low as 0.2, the results begin to change. In particular, the slope coefficients reported in Table 9 become implausibly large due to high levels of estimation error.
} 


\subsection{Model estimation results about the geographic distribution of hu- man capital}

Tables 7 through 11 describe how migration and intergenerational transmission interact with skills of labor markets. The results suggest a recent divergence of local human capital at the $\mathrm{CZ}$ level. Intergenerational transmission causes some regression to the mean of skills across CZs, as it does across states. Migration works against this tendency across CZs, unlike across states. That is, migration transfers more skills to CZs that had higher parent skills and thereby causes the skill divergence. Intergenerational transmission transfers skills toward smaller and more rural labor markets, while migration transfers skills toward larger and more urban labor markets. Overall, CZs that gain more skills tend to be larger and to have lower temperatures in January, higher supplies of higher education services, higher taxes on wages, and lower taxes on capital.

Table 7 displays descriptive statistics of model estimates for CZs. The variation in skills across CZs is dramatic. Take, for example, the parent generation skill ratios estimated with the 1990 Census. They range from 0.28 to 1.87. Also, the skewness of the distribution of skills across CZs at adult residence (2.26) is higher than the skewness of the child skill distribution (0.81). Migration contributes to skewness in the skill ratio distribution, as a few CZs accumulate high rates of skill. The average of $\Lambda_{j g}$ being less than one and the average of $M_{j g}$ being greater than one reflect the fact that movers tend to have more human capital than stayers.

Table 8 lists correlations between parameters from the model. The correlation between intergenerational transmission's effect on the skill ratio $\left(K_{j g} / S_{j g-1}\right)$ and pre-existing skill $\left(S_{j g-1}\right)$ is -0.471 . This reflects mean reversion in skills through intergenerational transmission. The correlation between the total migration effect on the skill ratio $\left(\Lambda_{j g} M_{j g}\right)$ and the parent generation skills $\left(S_{j g-1}\right)$, on the other hand, is positive (0.258). So, migration across CZs tends to work against the mean reversion due to intergenerational transmission.

In addition, skills of the previous generation's adults predict skills of the next genera- 
tion's adults: the correlation between skill ratios $S_{j g-1}$ and $S_{j g}$ is 0.546 . The intergenerational transmission effect on skills is negatively correlated with the total migration effect on skills. That is, the correlation between $K_{j g} / S_{j g-1}$ and $\Lambda_{j g} M_{j g}$ is -0.25 . This is consistent with intergenerational transmission moving skills to smaller labor markets and migration moving skills to larger labor markets, on which I elaborate below. Native retention of skills $\left(\Lambda_{j g}\right)$ is negatively correlated with in-migration of skills $\left(M_{j g}\right)$; this correlation is -0.395 .

Model estimation with the NELS:88 adds extra sampling variation to estimates relying only on Census data. Comparisons between the standard deviation and skewness of $S_{j g-1}$ and other parameters such as $K_{j g}$ and $S_{j g}$ may be misleading, since $S_{j g-1}$ is estimated with 1990 Census data only. In particular, the standard deviation of $S_{j g-1}$ being lower than the standard deviations of $K_{j g}$ and $S_{j g}$ may be the result of sampling variation rather than an increase in the inequality of skills across CZs over time. In addition, extra variation of a variable that is bounded below by zero, like these ratios, likely induces right skewness. So, I do not emphasize the difference in skewness between the distributions of $S_{j g-1}$ and $K_{j g}$.

I turn next to quantifying the effects of intergenerational transmission and migration on the generation-to-generation persistence of CZ skills. Unlike the state-level analysis, correction for sampling error here makes a large difference in the results. Throughout, I prefer the estimates that correct for bias from sampling error ${ }^{28}$

Column 1 of Table 9 displays results from a regression of the log skill ratio for adults in a $\mathrm{CZ}$ on the log skill ratio in that $\mathrm{CZ}$ of the previous generation. The slope coefficient is greater than one, so there appears to be some divergence of human capital at the CZ level. This finding is consistent with work by Berry and Glaeser (2005) and Moretti (2004b) at the MSA level. In general, the sampling error correction yields slope estimates further

\footnotetext{
${ }^{28}$ The correction follows Deaton (1985) as described in Footnote 10. I estimate the joint distribution of sampling error in model estimates $\left(K_{j g}, \Lambda_{j g}\right.$, etc.) with a parametric bootstrap procedure. I take 5,000 draws from the asymptotic distributions of parameter estimates in the intermediate probit and logit models and also from the sampling distribution of 1990 Census estimates. With these, I generate 5,000 vectors of the model estimates $\left(K_{j g}, \Lambda_{j g}\right.$, etc.) and calculate their joint distribution (variances and covariances).
} 
from zero than OLS estimates, as would be the case with classical measurement error.

Column 2 of Table 9 has results from a regression where the dependent variable is the log skill ratio among children in the CZ. This is the same as a prediction of what the CZ's adult log skill ratio would be if there were no migration. The independent variable in the regression is the previous generation's log skill ratio. The coefficient estimate is 0.819 , indicating that intergenerational transmission contributes to mean reversion in CZ skills.

Similar to the state level analysis, the degree of human capital persistence at the commuting zone level is greater than previous estimates of human capital persistence at the family level. The literature attempting to identify neighborhood effects has typically not found large effects (see Solon (1999)), and the evidence here is somewhat indirect. However, Column 2 of Table 9 suggests that there exist commuting zone characteristics that affect skill acquisition of children. The analysis below suggests that local higher education may play a role, but identification of causal mechanisms is beyond the scope of this paper.

Migration off-sets mean reversion by moving more skills to CZs with higher parents' skills. The regression in Column 3 of Table 9 has as its dependent variable the total effect of migration on the $\mathrm{CZ}$ skill ratio $\left(\ln \left(\Lambda_{j g} M_{j g}\right)\right)$. The estimated slope is positive, showing that migration works against intergenerational transmission by transferring skills toward CZs with higher skills in the previous generation.

Columns 4 and 5 of Table 9 decompose the migration effect into parts due to native retention of skills and in-migration of skills. The correlation between parent skills $\left(\ln \left(S_{j g-1}\right)\right)$ and native retention of skills $\left(\ln \left(\Lambda_{j g}\right)\right)$ is basically zero, which implies that more-skilled and less-skilled CZs tend to lose skills when natives leave about equally. However, the overall relationship between previous generation skills and skilled migration is positive, because more-skilled CZs gain skills at a significantly higher rate through in-migration $\left(\ln \left(M_{j g}\right)\right)$ than less-skilled CZs.

Tables 10 and 11 display results from regressions of model estimates on CZ characteristics. Overall, the results show that small labor markets lose skilled workers at high 
rates through migration. Other local characteristics - such as higher education policy, weather, and taxes - also affect the local skill mix. The intergenerational transmission of skills contributes to mean reversion of local skills, as small CZs gain more than larger CZs. Skilled migration, on the other hand, contributes to persistence of inter-location inequality in skills, as large and urban CZs with the highest skill levels among the previous generation gain the most skills through migration.

Table 10 displays a series of regressions whose dependent variables are model estimates describing how the intergenerational transmission and migration mechanisms affect the skill ratio of a CZ. The independent variables are $\mathrm{CZ}$ characteristics. The first column has $\ln \left(K_{j g} / S_{j g-1}\right)$ as its dependent variable; this is an estimate of the effect of intergenerational transmission on the CZ's skill ratio. Smaller CZs gain more skill through intergenerational transmission than larger CZs, and small towns gain the most.

Local college enrollment and state college subsidies are positively correlated with skill gains through intergenerational transmission. College subsidies conditional on state tax levels proxy for the emphasis placed on higher education in the state budget. Conditional on state taxes and other controls, an increase in this subsidy of 10 percent is correlated with an increase in the rate of skill gain through intergenerational transmission of 1.6 percent. This is consistent with subsidies causing an increase in skill investment, although I cannot interpret this coefficient as measuring a causal effect.

Column 2 of Table 10 identifies local correlates with the degree to which migration behavior shifts the local skill distribution $\left(\ln \left(\Lambda_{j g} M_{j g}\right)\right)$. This specification follows Equation 11 from the model. Western labor markets (the omitted region category) gain the most skill through migration. Small and rural labor markets acquire significantly less skill through migration than large cities.

CZs with colder winters (measured with average January temperature) gain more skill through migration than warmer labor markets. College enrollment per capita and state college subsidies are both positively correlated with skill gains through migration, although the coefficient on the enrollment variable is not statistically distinguishable from 
zero. Conditional on the other characteristics, there is not a strong relationship between local taxation and skill gains through migration.

The next two columns of Table 10 explore separately the two mechanisms underlying the total migration effect on the $\mathrm{CZ}$ skill ratio. The dependent variable in Column 3 is the relative native retention rate of skills $\left(\ln \left(\Lambda_{j g}\right)\right)$. Major metropolitan areas retain skills at the highest rates, and larger rural labor markets lose the most skills through out-migration. CZs with more manufacturing activity tend to retain more skills, conditional on other traits.

The dependent variable in Column 4 is the effect of in-migration on the CZ skill ratio $\left(\ln \left(M_{j g}\right)\right)$. Small rural CZs experience much less skilled in-migration than major metropolitan areas. Skilled migrants appear to be drawn to colder CZs. More-skilled migrants appear to value college subsidies more than less-skilled migrants. CZs with a higher manufacturing share of industry tend to gain less skill through in-migration.

Table 11 displays correlates with CZ skill ratios, rather than mechanisms that change skill ratios. The dependent variable of Column 1 is the natural logarithm of the skill ratio of native children, $\ln \left(K_{j g}\right)$. Conditional on contemporaneous labor market characteristics, metropolitan areas have higher-skilled children than the larger rural labor markets but not small towns.

Warmer Januaries are negatively correlated with native skills. An increase in average January temperature of 10 degrees (F.) is correlated with a decrease of the native children skill ratio of about 25 percent. The native children skill ratio is increasing in college enrollment and the subsidy rate for college. The highest proportions of skilled children are in the Northeast.

Column 2 of Table 11 displays results from regressing the natural logarithm of adult (post-migration) skill ratios $\left(\ln \left(S_{j g}\right)\right)$ on $\mathrm{CZ}$ characteristics. Adult skill ratios increase in CZ size. In addition, CZs with colder Januaries and more higher education supply tend to have higher skill ratios. CZs in states with lower capital taxes tend to have higher skills. Higher manufacturing shares predict lower skills conditional on other controls. 


\subsection{Local characteristics and local skills}

It is clear that larger and more-urban labor markets have higher skill levels among adults than smaller and more-rural labor markets. My findings indicate that migration continually reinforces this difference by sending highly-skilled children from all origins toward cities. Researchers are still refining our understanding of the reasons behind the clustering of highly-skilled people in metropolitan areas. One hypothesis is that cities are productive places where skilled workers meet, exchange ideas, and benefit from each others' productivity. Glaeser (1999) formalizes this idea. Glaeser and Maré (2001) provide evidence of wage growth effects of living in a city, which are consistent with this framework.

Another potential (not necessarily competing) hypothesis is that higher-skilled people have stronger preferences for living in cities than lower-skilled people. Florida (2002) emphasizes local amenities as important for drawing skilled people to a local area. Brueckner, Thisse, and Zenou (1999) present a model in which people with high incomes locate in high-amenity areas because their utility increases in local amenities faster than the utility of people with low incomes. The types of local amenities that are proposed to draw high-skilled people include those more common in cities than rural areas (for example, museums and diverse restaurants). Amenities may also play a role in determining the skill level of a local labor market without respect to its size.

The empirical evidence about local amenities and skills is mixed. Carlino and Saiz (2008) infer amenability from a measure of leisure visits to an MSA. They find that the share of population with bachelor's degrees grew faster in the 1990s in cities with more leisure visits in 1992. However, in most specifications of a regression of log leisure visits on MSA characteristics in a cross-section, the coefficient on share of population with bachelor's degrees is negative, though imprecisely estimated.

I find evidence that a positive amenity, average January temperature, is negatively correlated with local skill levels and with skilled migration. This is consistent with a model of location sorting by comparative advantage in which more-productive local labor 
markets reward high-skilled workers (with higher wages) more than low-skilled workers, while all workers value average January temperature the same. The evidence highlights a trade-off between productivity and amenability of local labor markets. ${ }^{29}$ However, it is also consistent with other positive amenities (like museums and restaurants) attracting high-skilled residents.

I find that the local supply of college services is positively correlated with the local skill level and also with the effect of migration on local skills. ${ }^{30}$ The estimates here assume that college supply factors are exogenous. It is likely, however, that other factors influencing skilled migration are correlated with local college supply. An example is a local industry that both supports local university research and also hires many college graduates from outside the area. So, I cannot infer from this analysis what would be the causal effect of building or expanding a local college on the local skill level.

I also find a negative correlation between capital taxation and local skill levels, which may reflect one of several underlying causes. There may be unobserved government services that are correlated with taxation and valued differently by high-skilled and lowskilled people. Alternatively, governments may respond to pre-existing local skill levels (and incomes) when making tax policy. So, I cannot infer a causal effect of taxation on local skills. However, my findings are consistent with research that shows people with high incomes moving away from areas with high taxes (see Bakija and Slemrod (2004) and Feldstein and Wrobel (1998)).

\footnotetext{
${ }^{29}$ Using data for U.S. counties, Rappaport (2007) finds a positive partial correlation between January temperature and population growth between 1970 and 2000, and he argues that rising incomes over time are the best explanation of the trend. His Table 4 shows a slightly larger relationship between January temperature and growth among college non-graduates than among college graduates, though both relationships are positive. His findings are consistent with those I present here: that higher January temperatures appear to attract lower-skilled residents more strongly than higher-skilled residents.

${ }^{30}$ Bound, Groen, Kezdi, and Turner (2004) and Abel and Deitz (2009) report positive correlations between college degree production and college degree stocks at the state and MSA levels, respectively.
} 


\section{Conclusion}

This paper examines the evolution and determinants of local labor market human capital levels. The framework decomposes labor market supplies of skills into the previous generation's skills, the intergenerational transmission of skill from local parents to their children, and the migration of people with different skill levels. Using a combination of Census and NELS:88 data sets, I estimate how the three factors interact to determine levels and changes over time of human capital in U.S. local labor markets.

Intergenerational transmission and migration contribute to the dynamics of local skills. From one generation to the next, I find mean reversion in local human capital at the state level but divergence of skills at the CZ level. Intergenerational transmission induces mean reversion in states and CZs. Migration works against this mechanism at the $\mathrm{CZ}$ level as CZs with higher skills in the previous generation gain more skill through migration. In this way, selective migration induces an increase of skill inequality across CZs in the data covering the 1990s.

Labor market size plays an important role in the dynamics of local human capital. In any cohort of adults, the highest-skilled labor markets are large cities. Mean reversion of local skills through intergenerational transmission manifests in smaller and more-rural CZs gaining skill while larger and more-urban CZs lose skill. Migration, however, allocates skill toward larger and more-urban CZs at the expense of smaller and more-rural CZs. Many of the most skilled natives of all CZs migrate away from their origins, but highly-skilled in-migrants are rare in rural CZs and much more common in urban CZs.

I also estimate correlations between other labor market characteristics and local human capital levels and changes. Skilled migrants are drawn to the West and to colder climates. The relationship between local college supply factors and skilled migration is positive and substantial. Skill growth is higher in states with lower capital taxes.

I hope the descriptive evidence in this paper leads to more research into the causes underlying the geographic distribution of human capital and how it changes over time. 
For example, it would be useful from a policy perspective to estimate the causal effect of local college supply on local skills and skilled migration. The challenge would be to find some variation in local college supply that is orthogonal to other causes of skilled migration. Since colleges typically open and close infrequently and expand slowly, it is difficult to find such variation at the institutional level. Tuition policies may display more useful variation.

\section{References}

[1] Abel, Jaison R. and Richard Deitz (2009) “Do Colleges and Universities Increase Their Region's Human Capital?" Federal Reserve Bank of New York Staff Reports No. 401.

[2] Acemoglu, Daron and Joshua Angrist (2000) "How Large are the Social Returns to Education? Evidence from Compulsory Schooling Laws" NBER Macroannual 9-59.

[3] Autor, David and David Dorn (2008) "Inequality and Specialization: The Growth of Low-Skill Service Jobs in the United States" MIT Working Paper.

[4] Bakija, Jon and Joel Slemrod (2004) "Do the Rich Flee from High State Taxes? Evidence from Federal Estate Tax Returns" NBER Working Paper 10645.

[5] Basker, Emek (2003) “Education, Job Search and Migration” mimeo.

[6] Behrman, Jere R. and Mark R. Rosenzweig (2002) “Does Increasing Women's Schooling Raise the Schooling of the Next Generation?" American Economic Review 92(1) 323-334.

[7] Berry, Christopher R. and Edward L. Glaeser (2005) “The Divergence of Human Capital Levels across Cities" Papers in Regional Science 84(3) 407-444. 
[8] Björklund, Anders, Mikael Lindahl, and Erik Plug (2006) “The Origins of Intergenerational Associations: Lessons from Swedish Adoption Data" The Quarterly Journal of Economics 121(3) 999-1028.

[9] Black, Sandra E., Paul J. Devereux, and Kjell G. Salvanes (2005) “Why the Apple Doesnt Fall Far: Understanding Intergenerational Transmission of Human Capital" American Economic Review 95(1) 437-449.

[10] Borjas, George J., Stephen G. Bronars, and Stephen J. Trejo (1992) "Self-Selection and Internal Migration in the United States" Journal of Urban Economics 32, 159-185.

[11] Bound, John, J. Groen, G. Kezdi, and Sarah E. Turner (2004) “Trade in University Training: Cross-State Variation in the Production and Stock of College-Educated Labor" Journal of Econometrics 121 (1-2): 143-173.

[12] Bound, John and Harry J. Holzer (2000) “Demand Shifts, Population Adjustments, and Labor Market Outcomes during the 1980s" Journal of Labor Economics 18(1) 20-54.

[13] Bowles, Samuel (1970) “Migration as Investment: Empirical Tests of the Human Investment Approach to Geographical Mobility" The Review of Economics and Statistics 52(4) 356-362.

[14] Brueckner, Jan K., Jacques-Francois Thisse, and Yves Zenou (1999) “Why Is Central Paris Rich and Downtown Detroit Poor? An Amenity-Based Theory" European Economic Review 43, 91-107.

[15] Carlino, Gerald A. and Albert Saiz (2008) "City Beautiful" IZA Discussion Paper 3778.

[16] Ciccone, Antonio and Giovanni Peri (2006) "Identifying Human-Capital Externalities: Theory with Applications" Review of Economic Studies 73(2) 381-412.

[17] Courchene, Thomas J. (1970) “Interprovincial Migration and Economic Adjustment" The Canadian Journal of Economics 3(4) 550-576. 
[18] Dahl, Gordon B. (2002) “Mobility and the Return to Education: Testing a Roy Model with Multiple Markets" Econometrica 70(6) 2367-2420.

[19] Deaton, Angus (1985) "Panel Data from a Time Series of Cross-Sections" Journal of Econometrics 30, 109-126.

[20] Feenberg, Daniel. “Maximum State Income Tax Rates, 1977-2005.” Data accessed at URL: <http://www.nber.org/ taxsim/state-rates/ > .

[21] Feenberg, Daniel Richard, and Elizabeth Coutts (1993) "An Introduction to the TAXSIM Model" Journal of Policy Analysis and Management 12(1) 189-194.

[22] Feldstein, Martin and Marian Vaillant Wrobel (1998) “Can State Taxes Redistribute Income?" Journal of Public Economics 68(3) 369-396.

[23] Florida, Richard (2003) The Rise of the Creative Class (New York: Basic Books).

[24] Fortin, Nicole M. (2006) “Higher-Education Policies and the College Wage Premium: Cross-State Evidence from the 1990s" The American Economic Review 96(4) 959-987. Data accessed at URL: <http://www.e-aer.org/ > .

[25] Glaeser, Edward L. (1999) “Learning in Cities” Journal of Urban Economics 46, 254-277.

[26] Glaeser, Edward L. and David C. Maré (2001) "Cities and Skills" Journal of Labor Economics 19(2) 316-342.

[27] Glaeser, Edward L., Matthew G. Resseger, and Kristina Tobio (2008) “Urban Inequality" NBER Working Paper 14419.

[28] Glaeser, Edward L. and Albert Saiz (2003) "The Rise of the Skilled City" NBER Working Paper 10191.

[29] Greenwood, Michael J. (1997) "Internal Migration in Developed Countries" Chapter 12 in M.R. Rosenzweig and O. Stark, eds. Handbook of Population and Family Economics (Elsevier Science) 648-720. 
[30] Ham, John C., Xianghong Li, and Patricia B. Reagan (2006) “Propensity Score Matching, a Distance-Based Measure of Migration, and the Wages of Young Men" mimeo.

[31] Kodrzycki, Yolanda K. (2000) “New Englands Educational Advantage: Past Successes and Future Prospects" New England Economic Review , January/February, 2540.

[32] Kodrzycki, Yolanda K. (2001) "Migration of Recent College Graduates: Evidence from the National Longitudinal Survey of Youth" New England Economic Review , January/February, 13-34.

[33] Lange, Fabian and Robert Topel (2006) “The Social Value of Education and Human Capital" in Eric Hanushek and Finis Welch, eds. Handbook of Education Economics Volume 1.

[34] Malamud, Ofer and Abigail Wozniak (2008) "The Impact of College Graduation on Geographic Mobility: Identifying Education Using Multiple Components of Vietnam Draft Risk" mimeo.

[35] McFadden, Daniel (1974) “Conditional Logit Analysis of Qualitative Choice Behavior" in P. Zarembka, ed. Frontiers in Econometrics New York: Academic Press, 105-142.

[36] McHenry, Peter (2008) "The Relationship between Schooling and Migration: Evidence from Compulsory Schooling Laws" mimeo.

[37] Moretti, Enrico (2004a) "Estimating the Social Return to Higher Education: Evidence from Longitudinal and Repeated Cross-sectional Data" Journal of Econometrics 121 $175-212$.

[38] Moretti, Enrico (2004b) “Human Capital Externalities in Cities" Chapter 51 in J. Vernon Henderson and Jacques-Franqois Thissel, Eds. Handbook of Regional and Urban Economics Volume 4. North Holland-Elsevier, 2243-2291. 
[39] Rappaport, Jordan (2007) "Moving to Nice Weather" Regional Science and Urban Economics 37 375-398.

[40] Rauch, James (1993) "Productivity Gains from Geographic Concentration in Cities" Journal of Urban Economics 34 380-400.

[41] Roy, A.D. (1951) "Some Thoughts on the Distribution of Earnings" Oxford Economic Papers 3(2) 135-146.

[42] Ruggles, Steven, Matthew Sobek, Trent Alexander, Catherine A. Fitch, Ronald Goeken, Patricia Kelly Hall, Miriam King, and Chad Ronnander (2004) Integrated Public Use Microdata Series: Version 3.0 [Machine-readable database]. Minneapolis, MN: Minnesota Population Center [producer and distributor].

[43] Sacerdote, Bruce (2007) "How Large Are the Effects from Changes in Family Environment? A Study of Korean American Adoptees" The Quarterly Journal of Economics 122(1) 119-158.

[44] Schultz, T. Paul (1971) "Rural-Urban Migration in Colombia" The Review of Economics and Statistics 53(2) 157-163.

[45] Solon, Gary (1999) "Intergenerational Mobility in the Labor Market" Chapter 29 in O. Ashenfelter and D. Card, eds. Handbook of Labor Economics Volume 3. (Elsevier Science) $1761-1800$.

[46] Tolbert, Charles M. and Molly Sizer (1996) “U.S. Commuting Zones and Labor Market Areas. A 1990 Update." Economic Research Service Staff Paper No. 9614.

[47] U.S. Census Bureau. "ZCTAs (ZIP Code Tabulation Areas)". Data file accessed at URL: <http://www.census.gov/geo/www/gazetteer/places2k.html >.

[48] U.S. Census Bureau (2005) Table No. 212. “Educational Attainment by Race and Hispanic Origin: 1960 to 2003" Statistical Abstract of the United States: 2004-2005. Avail- 
able at: <http://www.census.gov/prod/www/statistical-abstract-2001_2005.html $>$.

[49] U.S. Department of Commerce. National Climatic Data Center. Data accessed at URL: <http://cdo.ncdc.noaa.gov/pls/plclimprod/somdmain.somdwrapper? datasetabbv $=\mathrm{DS} 3220 \&$ countryabbv $=\&$ georegionabbv $=.>$.

[50] U.S. Department of Education. National Center for Education Statistics. Integrated Postsecondary Education Data System. Data accessed at URL: $<$ http://www.nces.ed.gov/ipedspas/dct/index.asp $>$.

[51] Wozniak, Abigail (2006) “Why Are College Graduates More Responsive to Distant Labor Market Opportunities?" mimeo.

[52] ZipInfo.com. <http://www.zipinfo.com/products/products.htm $>$.

\section{Figures and Tables}


Figure 1: Timing of the OLG Model
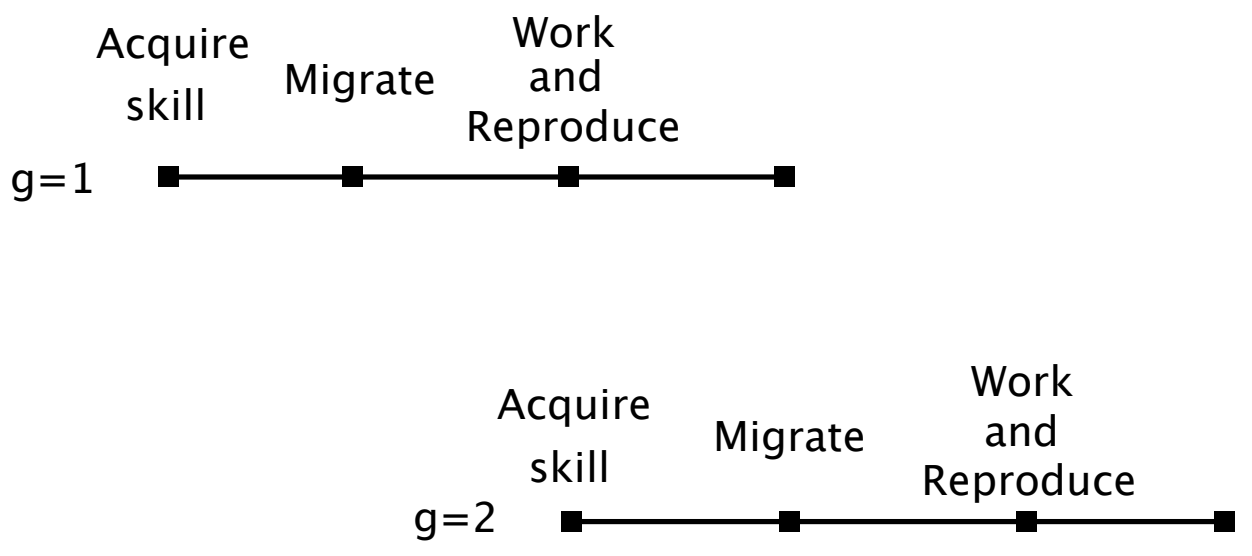

Figure 2: Migration by Age, 2000 Census

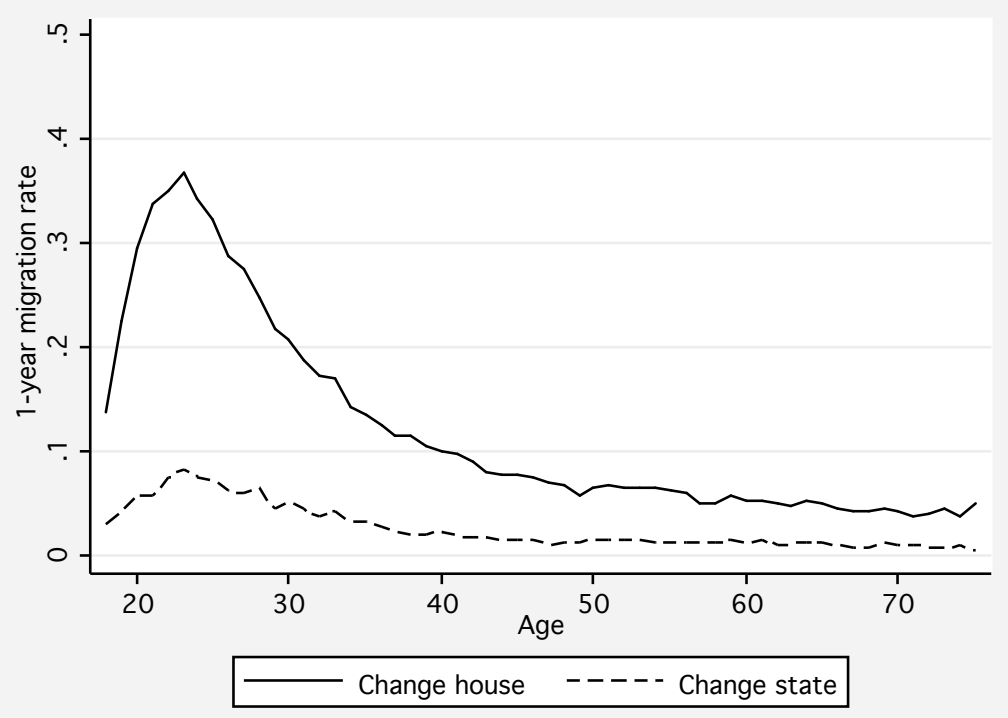


Table 1: Commuting Zones with Highest and Lowest Percent College, 2000

\begin{tabular}{|c|c|c|c|c|c|}
\hline (1) & (2) & (3) & (4) & (5) & (6) \\
\hline Rank & Name & Percent & Rank & Name & Percent \\
\hline 1 & Washington, D.C. & 44.3 & 732 & Corbin, KY & 10.4 \\
\hline 2 & Kremmling, $\mathrm{CO}$ & 42.7 & 733 & Henderson, KY & 10.4 \\
\hline 3 & Gunnison, CO & 42.7 & 734 & Pikeville, KY & 10.4 \\
\hline 4 & Boston, MA & 40.1 & 735 & Jonesville, LA & 10.4 \\
\hline 5 & San Francisco, CA & 39.3 & 736 & Waycross, GA & 10.2 \\
\hline 6 & Glenwood Springs, CO & 38.5 & 737 & Campbellsville, KY & 10 \\
\hline 7 & San Jose, CA & 37.6 & 738 & Somerset, KY & 9.7 \\
\hline 8 & Vineyard Haven CDP, MA & 37.6 & 739 & Hazard, KY & 9.6 \\
\hline 9 & Nantucket CDP, MA & 37.6 & 740 & Middlesborough, KY & 9.1 \\
\hline 10 & Denver, CO & 37.4 & 741 & Glasgow, KY & 8.8 \\
\hline \multicolumn{6}{|c|}{ Among CZs containing an MSA } \\
\hline 1 & Washington, D.C. & 44.3 & 249 & Bakersfield, CA & 14.2 \\
\hline 2 & Boston, MA & 40.1 & 250 & Morganton, NC & 14.1 \\
\hline 3 & San Francisco, CA & 39.3 & 251 & Goldsboro, NC & 14.1 \\
\hline 4 & San Jose, CA & 37.6 & 252 & Parkersburg, WV & 13.9 \\
\hline 5 & Denver, CO & 37.4 & 253 & Brownsville, TX & 13.3 \\
\hline 6 & Austin, TX & 37 & 254 & Mansfield, $\mathrm{OH}$ & 12.7 \\
\hline 7 & Raleigh, NC & 36.9 & 255 & Gadsden, AL & 12.4 \\
\hline 8 & Madison, WI & 36.8 & 256 & Yuma, AZ & 12 \\
\hline 9 & Newark, NJ & 36.3 & 257 & Houma, LA & 11.6 \\
\hline 10 & Minneapolis, MN & 35.9 & 258 & Henderson, KY & 10.4 \\
\hline
\end{tabular}


Table 2: Accounting for Skills across States, Census

\begin{tabular}{|c|c|c|c|c|c|c|}
\hline Description & Variable & $\begin{array}{c}(1) \\
\text { Mean }\end{array}$ & $\begin{array}{c}\text { (2) } \\
\text { StDev }\end{array}$ & $\begin{array}{c}\text { (3) } \\
\text { Skew }\end{array}$ & $\begin{array}{l}\text { (4) } \\
\text { Min }\end{array}$ & $\begin{array}{l}\text { (5) } \\
\text { Max }\end{array}$ \\
\hline Parent gen. skill ratio & $S_{j g-1}$ & 1.03 & .26 & .25 & .56 & 1.68 \\
\hline Child skill ratio & $K_{j g}$ & .99 & .27 & .27 & .53 & 1.63 \\
\hline Stayers skill ratio & $K_{j g} \Lambda_{j g}$ & .71 & .24 & .71 & .38 & 1.37 \\
\hline Adult skill ratio & $S_{j g}$ & .96 & .29 & .67 & .49 & 1.76 \\
\hline Intergenerational factor & $K_{j g} / S_{j g-1}$ & .98 & .23 & .82 & 48 & 1.83 \\
\hline Native retention factor & $\Lambda_{j g}$ & .71 & 11 & -.89 & .3 & .98 \\
\hline In-migration factor & $M_{j q}$ & 1.42 & .45 & 3.75 & 1.05 & 3.95 \\
\hline Total migration factor & $\Lambda_{j q}^{j} M_{i q}$ & .99 & .21 & .52 & .64 & 1.47 \\
\hline
\end{tabular}

Notes: Estimates from accounting exercise described in Section 3. Estimates for generation $g-1$ from 1980 Census and for generation $g$ from 2000 Census.

Table 3: Correlations between Accounting Exercise Characteristics of States, Census

\begin{tabular}{lcccccccc}
\hline \hline & $(1)$ & $(2)$ & $(3)$ & $(4)$ & $(5)$ & $(6)$ & $(7)$ & $(8)$ \\
& $S_{j g-1}$ & $K_{j g}$ & $K_{j g} \Lambda_{j g}$ & $S_{j g}$ & $K_{j g} / S_{j g-1}$ & $\Lambda_{j g}$ & $M_{j g}$ & $\Lambda_{j g} M_{j g}$ \\
\cline { 2 - 9 }$S_{j g-1}$ & 1 & & & & & & & \\
$K_{j g}$ & .53 & 1 & & & & & & \\
$K_{j g} \Lambda_{j g}$ & .545 & .851 & 1 & & & & & \\
$S_{j g}$ & .516 & .738 & .746 & 1 & & & & \\
$K_{j g} / S_{j g-1}$ & -.376 & .557 & .313 & .316 & 1 & & & \\
$\Lambda_{j g}$ & .143 & .03 & .539 & .263 & -.227 & 1 & & \\
$M_{j g}$ & -.115 & -.109 & -.383 & .303 & .154 & -.509 & 1 & \\
$\Lambda_{j g} M_{j g}$ & .032 & -.26 & -.059 & .443 & -.281 & .336 & .566 & 1 \\
\hline
\end{tabular}

Notes: Estimates from accounting exercise described in Section 3. Estimates for generation $g-1$ from 1980 Census and for generation $g$ from 2000 Census. 
Table 4: Generation-to-Generation Persistence of Skills across States, Census, 1980-2000

\begin{tabular}{|c|c|c|c|c|c|}
\hline VARIABLES & $\begin{array}{c}(1) \\
\text { Adult skill } \\
\text { ratio } \\
\ln \left(S_{j g}\right)\end{array}$ & $\begin{array}{c}(2) \\
\text { Child skill } \\
\text { ratio } \\
\ln \left(K_{j g}\right)\end{array}$ & $\begin{array}{c}(3) \\
\text { Migration } \\
\text { effect } \\
\ln \left(\Lambda_{j g} M_{j g}\right)\end{array}$ & $\begin{array}{c}(4) \\
\text { Native retention } \\
\text { effect } \\
\ln \left(\Lambda_{j g}\right)\end{array}$ & $\begin{array}{c}5) \\
\text { In-migration } \\
\text { effect } \\
\ln \left(M_{j g}\right)\end{array}$ \\
\hline $\ln \left(S_{j g-1}\right)$ & $\begin{array}{c}.6582^{* * *} \\
(.1341)\end{array}$ & $\begin{array}{l}.6738^{* * *} \\
(.1185)\end{array}$ & $\begin{array}{l}-.0156 \\
(.1142)\end{array}$ & $\begin{array}{c}.0865 \\
(.0962)\end{array}$ & $\begin{array}{l}-.1021 \\
(.1271)\end{array}$ \\
\hline Constant & $\begin{array}{c}-.0823^{* *} \\
(.0343)\end{array}$ & $\begin{array}{l}-.0475 \\
(.0303)\end{array}$ & $\begin{array}{l}-.0349 \\
(.0292)\end{array}$ & $\begin{array}{c}-.3505^{* * *} \\
(.0246)\end{array}$ & $\begin{array}{l}.3156^{* * *} \\
(.0325)\end{array}$ \\
\hline Observations & 51 & 51 & 51 & 51 & 51 \\
\hline R-squared & .321 & .388 & 0 & .016 & .012 \\
\hline
\end{tabular}

Notes: ${ }^{* *} \mathrm{p}<0.01{ }^{* *} \mathrm{p}<0.05^{*} \mathrm{p}<0.1$. Each column has results from a separate regression. Variables are estimates from accounting exercise described in Section 3. Dependent variable is the column heading, each derived using 2000 Census data. $\ln \left(S_{j g-1}\right)$ derived from 1980 Census. Estimates account for errors in variables as in Deaton (1985). Slope coefficient in Column 1 is the sum of slopes in Columns 2 and 3; slope coefficient in Column 3 is the sum of slopes in Columns 4 and 5.

Table 5: Characteristics of the 741 Commuting Zones, 2000

\begin{tabular}{lcccc}
\hline \hline & $\begin{array}{c}(1) \\
\text { Vean }\end{array}$ & $\begin{array}{c}(2) \\
\text { StDev }\end{array}$ & $\begin{array}{c}(3) \\
\text { Min }\end{array}$ & $\begin{array}{c}(4) \\
\text { Max }\end{array}$ \\
\cline { 2 - 5 } South & .394 & .489 & 0 & 1 \\
Midwest & .34 & .474 & 0 & 1 \\
West & .209 & .407 & 0 & 1 \\
Northeast & .057 & .231 & 0 & 1 \\
Coastal & .124 & .33 & 0 & 1 \\
Annual snow (in.) & 22.3 & 24.7 & 0 & 157.3 \\
Avg January temp (degF) & 31.8 & 12.3 & -23 & 70.4 \\
Avg July temp (degF) & 74.5 & 6.4 & 42.3 & 91.6 \\
Percent college degree & 20 & 6 & 8.8 & 44.3 \\
Percent unemployed & 5.6 & 2.1 & 2.5 & 16 \\
Avg weekly wage & 661 & 94 & 504 & 1160 \\
Percent manufacturing & 15.9 & 8.2 & 2.4 & 44.4 \\
Wage tax & 43.6 & 1.8 & 40.8 & 46.7 \\
Capital tax & 23.9 & 1.8 & 21.2 & 27.1 \\
Higher ed subsidy & 2.7 & 1.1 & .4 & 5.8 \\
College enrollment & 14648 & 38924 & 0 & 657298 \\
Census sample & 13986 & 24052 & 2289 & 390384 \\
Population & 379787 & 1047226 & 1193 & 16393360 \\
\hline Notes: Commuting zones are county groups with strong commuting ties. \\
They approximate labor markets and are defined in Tolbert and Sizer \\
(1996). See Section 5 for a description of data sources. Appendix A has \\
additional information.
\end{tabular}


Table 6: Characteristics of Respondents, by Move Status, NELS:88

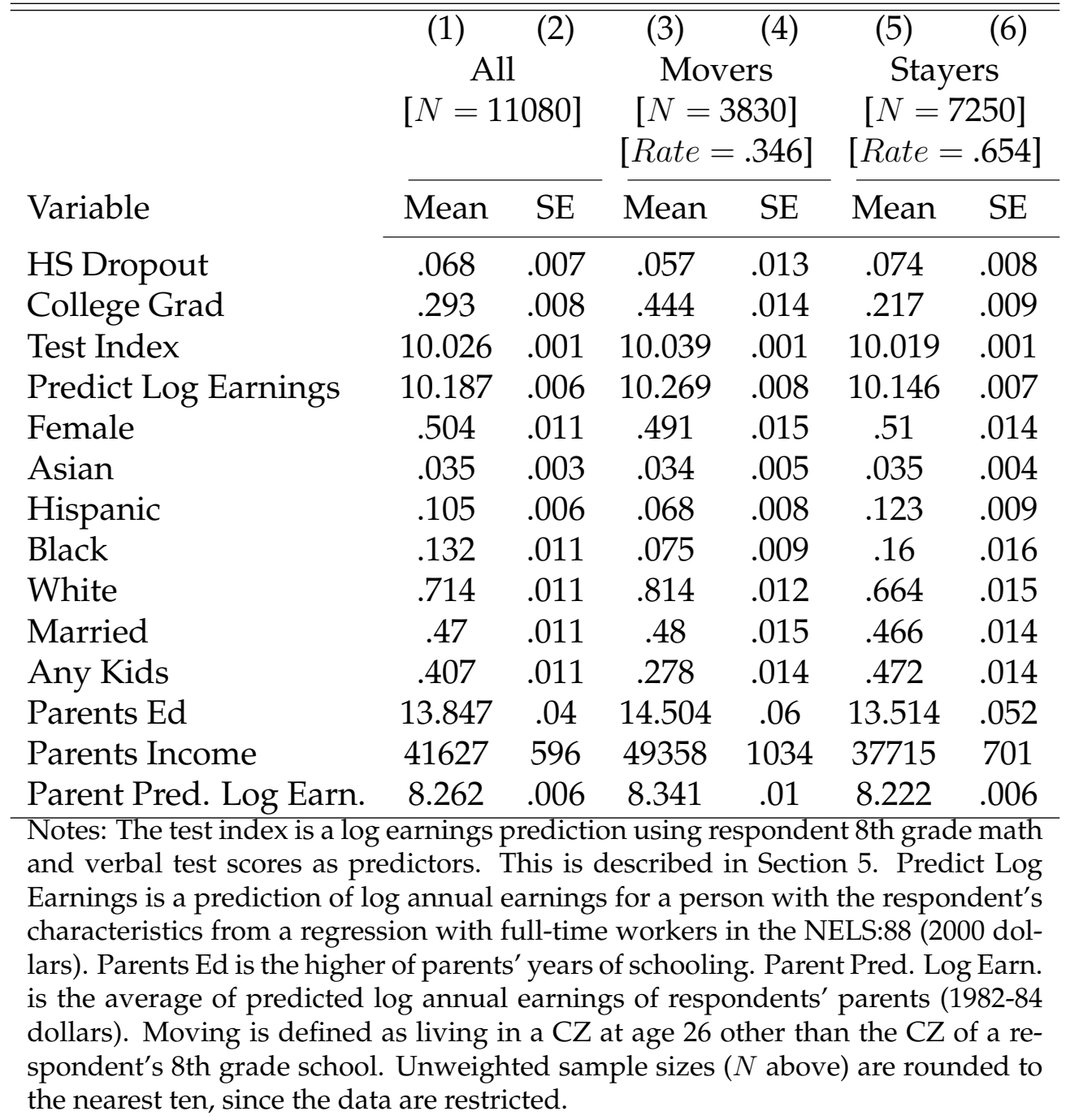


Table 7: Summary Statistics of Model Estimation, NELS:88, CZs

\begin{tabular}{|c|c|c|c|c|c|c|}
\hline & & $(1)$ & $(2)$ & (3) & (4) & (5) \\
\hline Description & Variable & Mean & StDev & Skew & Min & Max \\
\hline Parent gen. skill ratio & $S_{j g-1}$ & .85 & .28 & .67 & .28 & 1.87 \\
\hline Child skill ratio & $K_{j g}$ & 1.09 & .36 & .81 & .38 & 2.42 \\
\hline Stayers skill ratio & $K_{j g} \Lambda_{j g}$ & .74 & .49 & 5.27 & .12 & 5.41 \\
\hline Adult skill ratio & $S_{j g}$ & .99 & .46 & 2.26 & .3 & 3.83 \\
\hline Intergenerational factor & $K_{j g} / S_{j g-1}$ & 1.36 & .48 & 1.42 & .59 & 3.79 \\
\hline Native retention factor & $\Lambda_{j g}$ & .67 & .34 & 9.77 & .14 & 5.41 \\
\hline In-migration factor & $M_{j g}$ & 1.46 & .49 & 3.67 & .08 & 6.39 \\
\hline Total migration factor & $\Lambda_{j g} M_{j g}$ & .9 & .26 & 3.48 & .33 & 3.37 \\
\hline
\end{tabular}

Table 8: Correlations between Model Parameters, NELS:88, CZs

\begin{tabular}{lcccccccc}
\hline \hline & $(1)$ & $(2)$ & $(3)$ & $(4)$ & $(5)$ & $(6)$ & $(7)$ & $(8)$ \\
& $S_{j g-1}$ & $K_{j g}$ & $K_{j g} \Lambda_{j g}$ & $S_{j g}$ & $K_{j g} / S_{j g-1}$ & $\Lambda_{j g}$ & $M_{j g}$ & $\Lambda_{j g} M_{j g}$ \\
\cline { 2 - 8 }$S_{j g-1}$ & 1 & & & & & & & \\
$K_{j g}$ & .482 & 1 & & & & & & \\
$K_{j g} \Lambda_{j g}$ & .235 & .577 & 1 & & & & & \\
$S_{j g}$ & .546 & .732 & .564 & 1 & & & & \\
$K_{j g} / S_{j g-1}$ & -.471 & .491 & .324 & .174 & 1 & & & \\
$\Lambda_{j g}$ & -.017 & .078 & .831 & .154 & .102 & 1 & & \\
$M_{j g}$ & .176 & -.131 & -.367 & .266 & -.296 & -.395 & 1 & \\
$\Lambda_{j g} M_{j g}$ & .258 & -.013 & .116 & .622 & -.25 & .072 & .671 & 1 \\
\hline
\end{tabular}

Notes: Variables from model estimation described in Section 6.1. Estimates for generation $g-1$ from 1990 Census and for generation $g$ from NELS:88. Only includes the approximately $310 \mathrm{CZs}$ in the NELS:88 base year sample. 
Table 9: Generation-to-Generation Persistence of Skills across CZs, NELS:88

\begin{tabular}{lccccc}
\hline \hline & $\begin{array}{c}(1) \\
\text { Adult skill } \\
\text { ratio }\end{array}$ & $\begin{array}{c}\text { Child skill } \\
\text { ratio }\end{array}$ & $\begin{array}{c}(3) \\
\text { Migration } \\
\text { effect } \\
\ln \left(S_{j g}\right)\end{array}$ & $\begin{array}{c}\text { Native retention } \\
\text { effect }\end{array}$ & $\begin{array}{c}(5) \\
\text { In-migration } \\
\text { effect }\end{array}$ \\
$\ln \left(K_{j g}\right)$ & $\ln \left(\Lambda_{j g} M_{j g}\right)$ & $\ln \left(\Lambda_{j g}\right)$ & $\ln \left(M_{j g}\right)$ \\
\hline $\ln \left(S_{j g-1}\right)$ & 1.299 & 0.819 & 0.480 & -0.063 & 0.543 \\
& $(0.167)$ & $(0.120)$ & $(0.106)$ & $(0.110)$ & $(0.137)$ \\
Constant & .181 & .212 & -.031 & -.473 & .443 \\
& $(.042)$ & $(.031)$ & $(.027)$ & $(.029)$ & $(.035)$ \\
Observations & 310 & 310 & 310 & 310 & 310 \\
\hline
\end{tabular}

Notes: Each column has results from a separate regression. Variables from model estimation described in Section 6.1. Dependent variable is the column heading, each derived using NELS:88. $\ln \left(S_{j g-1}\right)$ derived from 1990 Census. Estimates account for errors in variables as in Deaton (1985). Slope coefficient in Column 1 is the sum of slopes in Columns 2 and 3; slope coefficient in Column 3 is the sum of slopes in Columns 4 and 5. Numbers of observations are rounded to the nearest ten, since the NELS:88 data are restricted. 
Table 10: Correlates with Model Estimates of Skill Flows

\begin{tabular}{|c|c|c|c|c|}
\hline VARIABLES & $\begin{array}{c}(1) \\
\text { Intergenerational } \\
\text { transmission } \\
\ln \left(K_{j g} / S_{j g-1}\right) \\
\end{array}$ & $\begin{array}{c}(2) \\
\text { Total } \\
\text { migration } \\
\ln \left(\Lambda_{j g} M_{j g}\right) \\
\end{array}$ & $\begin{array}{c}(3) \\
\text { Native } \\
\text { retention } \\
\ln \left(\Lambda_{j g}\right) \\
\end{array}$ & $\begin{array}{c}(4) \\
\text { In- } \\
\text { migration } \\
\ln \left(M_{j g}\right) \\
\end{array}$ \\
\hline South & $\begin{array}{c}.0784 \\
(.0561)\end{array}$ & $\begin{array}{c}-.178^{* * *} \\
(.049)\end{array}$ & $\begin{array}{l}-.327^{* * *} \\
(.0688)\end{array}$ & $\begin{array}{l}.149^{* *} \\
(.0703)\end{array}$ \\
\hline Midwest & $\begin{array}{l}.0742 \\
(.0562)\end{array}$ & $\begin{array}{l}-.294^{* * *} \\
(.0551)\end{array}$ & $\begin{array}{l}-.162^{* *} \\
(.0713)\end{array}$ & $\begin{array}{l}-.131^{* *} \\
(.0615)\end{array}$ \\
\hline Northeast & $\begin{array}{l}.15^{* * *} \\
(.0529)\end{array}$ & $\begin{array}{l}-.196^{* * *} \\
(.0535)\end{array}$ & $\begin{array}{l}-.256^{* * *} \\
(.0775)\end{array}$ & $\begin{array}{l}.0604 \\
(.0628)\end{array}$ \\
\hline Coastal & $\begin{array}{l}-.0294 \\
(.0333)\end{array}$ & $\begin{array}{c}.014 \\
(.0412)\end{array}$ & $\begin{array}{l}-.22^{* * *} \\
(.0624)\end{array}$ & $\begin{array}{l}.234^{* * *} \\
(.046)\end{array}$ \\
\hline Small town & $\begin{array}{l}.416^{* * *} \\
(.104)\end{array}$ & $\begin{array}{c}-.479^{* * *} \\
(.112)\end{array}$ & $\begin{array}{l}-.079 \\
(.224)\end{array}$ & $\begin{array}{l}-.4^{* * *} \\
(.151)\end{array}$ \\
\hline Small urban & $\begin{array}{l}.377^{* * *} \\
(.0486)\end{array}$ & $\begin{array}{l}-.257^{* * * *} \\
(.0479)\end{array}$ & $\begin{array}{l}-.0284 \\
(.0689)\end{array}$ & $\begin{array}{l}-.229^{* * *} \\
(.0795)\end{array}$ \\
\hline Larger urban & $\begin{array}{l}.336^{* * *} \\
(.0443)\end{array}$ & $\begin{array}{l}-.197^{* * * *} \\
(.0378)\end{array}$ & $\begin{array}{l}-.36^{* * *} \\
(.0364)\end{array}$ & $\begin{array}{l}.164^{* * *} \\
(.0424)\end{array}$ \\
\hline Small metro & $\begin{array}{l}.27^{* * *} \\
(.033)\end{array}$ & $\begin{array}{l}-.279 * * * * \\
(.0379)\end{array}$ & $\begin{array}{l}-.173^{* * *} \\
(.0284)\end{array}$ & $\begin{array}{l}-.106^{* * * *} \\
(.0394)\end{array}$ \\
\hline Medium metro & $\begin{array}{l}.125^{* * *} \\
(.0283)\end{array}$ & $\begin{array}{l}-.134^{* * *} \\
(.0332)\end{array}$ & $\begin{array}{l}-.139 * * * \\
(.0251)\end{array}$ & $\begin{array}{l}.00442 \\
(.0357)\end{array}$ \\
\hline Jan Temp (degF) & $\begin{array}{l}-.0164^{* * *} \\
(.00259)\end{array}$ & $\begin{array}{l}-.00756^{*} \\
(.00432)\end{array}$ & $\begin{array}{c}.00304 \\
(.00353)\end{array}$ & $\begin{array}{l}-.0106^{* *} \\
(.00506)\end{array}$ \\
\hline July Temp (degF) & $\begin{array}{l}.0121^{* *} \\
(.00481)\end{array}$ & $\begin{array}{l}.0141^{* * *} \\
(.00458)\end{array}$ & $\begin{array}{l}.0239^{* * *} \\
(.00556)\end{array}$ & $\begin{array}{l}-.00983^{*} \\
(.00531)\end{array}$ \\
\hline Ann. Snow (in) & $\begin{array}{l}-.000237 \\
(.000819)\end{array}$ & $\begin{array}{l}-.000401 \\
(.000957)\end{array}$ & $\begin{array}{l}.00237 \\
(.00151)\end{array}$ & $\begin{array}{l}-.00277^{* * *} \\
(.00109)\end{array}$ \\
\hline College enroll/Pop & $\begin{array}{l}1.48^{* *} \\
(.648)\end{array}$ & $\begin{array}{c}.254 \\
(.313)\end{array}$ & $\begin{array}{l}.712^{* *} \\
(.282)\end{array}$ & $\begin{array}{l}-.458 \\
(.367)\end{array}$ \\
\hline Ln(College subsidy) & $\begin{array}{l}.16^{* * *} \\
(.0335)\end{array}$ & $\begin{array}{l}.242^{* * *} \\
(.0404)\end{array}$ & $\begin{array}{l}-.0459 \\
(.0516)\end{array}$ & $\begin{array}{l}.288^{* * *} \\
(.0468)\end{array}$ \\
\hline Wage tax & $\begin{array}{l}.0449^{* * *} \\
(.0123)\end{array}$ & $\begin{array}{l}.0184 \\
(.0146)\end{array}$ & $\begin{array}{l}.0224 \\
(.0203)\end{array}$ & $\begin{array}{r}-.00399 \\
(.0162)\end{array}$ \\
\hline Capital tax & $\begin{array}{l}-.0902^{* * *} \\
(.0121)\end{array}$ & $\begin{array}{l}-.0176 \\
(.0128)\end{array}$ & $\begin{array}{c}-.0318^{*} \\
(.018)\end{array}$ & $\begin{array}{l}.0142 \\
(.0133)\end{array}$ \\
\hline$\%$ Manufacturing & $\begin{array}{l}.00716^{* * *} \\
(.00217)\end{array}$ & $\begin{array}{l}-.00142 \\
(.00172)\end{array}$ & $\begin{array}{c}.00815^{* * *} \\
(.0026)\end{array}$ & $\begin{array}{c}-.00957^{* * *} \\
(.00279)\end{array}$ \\
\hline Constant & $\begin{array}{c}-.528 \\
(.443)\end{array}$ & $\begin{array}{c}-1.15^{* *} \\
(.501)\end{array}$ & $\begin{array}{c}-2.37^{* * *} \\
(.629)\end{array}$ & $\begin{array}{c}1.23^{* *} \\
(.52)\end{array}$ \\
\hline Observations & 310 & 310 & 310 & 310 \\
\hline R-squared & 0.649 & 0.509 & 0.285 & 0.489 \\
\hline
\end{tabular}

Notes: ${ }^{* * *} \mathrm{p}<0.01^{* *} \mathrm{p}<0.05^{*} \mathrm{p}<0.1$. Each column has results from a separate OLS model with CZs as observations. Dependent variable is a mechanism's estimated effect on the CZ's skill ratio, where the mechanism is denoted by the column heading. Dependent variables from model estimation described in Section 6.1 using 1990 Census and NELS:88. $K_{j g}$ is the CZ's child skill ratio. $S_{j g-1}$ is the CZ's adult skill ratio in the previous generation. $\Lambda_{j g}$ and $M_{j g}$ are the effects of native retention and in-migration on the CZ skill ratio, respectively. Major metro area is the omitted CZ size category. West is the omitted $\mathrm{CZ}$ region. See text for definitions of other variables. Heteroskedasticity-robust standard errors in parentheses. Numbers of observations are rounded to the nearest ten, since the data are restricted. 
Table 11: Correlates with Model Estimates of Skill Stocks

\begin{tabular}{|c|c|c|}
\hline \multirow[b]{2}{*}{ VARIABLES } & (1) & (2) \\
\hline & $\ln \left(K_{j g}\right)$ & $\ln \left(S_{j g}\right)$ \\
\hline \multirow{2}{*}{ South } & .0336 & -.144 \\
\hline & $(.068)$ & (.0967) \\
\hline \multirow[t]{2}{*}{ Midwest } & .0312 & $-.262^{* * *}$ \\
\hline & $(.0662)$ & $(.0974)$ \\
\hline \multirow[t]{2}{*}{ Northeast } & .0814 & -.114 \\
\hline & $(.0672)$ & (.0995) \\
\hline \multirow[t]{2}{*}{ Coastal } & .0421 & .0561 \\
\hline & $(.0476)$ & $(.0694)$ \\
\hline \multirow[t]{2}{*}{ Small town } & -.0576 & $-.536^{* * *}$ \\
\hline & $(.1)$ & $(.157)$ \\
\hline \multirow[t]{2}{*}{ Small urban } & $-.232^{* * *}$ & $-.489^{* * *}$ \\
\hline & $(.0519)$ & $(.0753)$ \\
\hline \multirow[t]{2}{*}{ Larger urban } & $-.114^{* *}$ & $-.311^{* * *}$ \\
\hline & $(.0517)$ & $(.0667)$ \\
\hline \multirow[t]{2}{*}{ Small metro } & -.0486 & $-.327^{* * *}$ \\
\hline & $(.0446)$ & $(.0697)$ \\
\hline \multirow[t]{2}{*}{ Medium metro } & -.0504 & $-.184^{* * *}$ \\
\hline & $(.0405)$ & $(.0595)$ \\
\hline \multirow[t]{2}{*}{ Jan Temp (degF) } & $-.0221^{* * *}$ & $-.0297^{* * *}$ \\
\hline & $(.00268)$ & $(.00598)$ \\
\hline \multirow[t]{2}{*}{ July Temp (degF) } & -.000264 & .0138 \\
\hline & $(.00636)$ & $(.00856)$ \\
\hline \multirow{2}{*}{ Ann. Snow (in) } & -.000217 & -.000618 \\
\hline & $(.000978)$ & (.00159) \\
\hline \multirow[t]{2}{*}{ College enroll/Pop } & $1.97^{* *}$ & $2.23^{*}$ \\
\hline & $(.86)$ & $(1.14)$ \\
\hline \multirow[t]{2}{*}{ Ln(College subsidy) } & $.14^{* * *}$ & $.383^{* * *}$ \\
\hline & $(.0402)$ & $(.0672)$ \\
\hline \multirow[t]{2}{*}{ Wage tax } & .0000934 & .0185 \\
\hline & $(.0162)$ & $(.025)$ \\
\hline \multirow[t]{2}{*}{ Capital tax } & $-.0445^{* * *}$ & $-.0621^{* * *}$ \\
\hline & $(.016)$ & $(.0226)$ \\
\hline \multirow[t]{2}{*}{$\%$ Manufacturing } & $-.00439^{* *}$ & $-.0058^{* *}$ \\
\hline & $(.00212)$ & $(.00288)$ \\
\hline \multirow[t]{2}{*}{ Constant } & $1.78^{* * *}$ & .63 \\
\hline & $(.591)$ & $(.903)$ \\
\hline Observations & 310 & 310 \\
\hline R-squared & 0.561 & 0.412 \\
\hline \multicolumn{3}{|c|}{$\begin{array}{l}\text { Notes: }{ }^{* * *} \mathrm{p}<0.01{ }^{* *} \mathrm{p}<0.05^{*} \mathrm{p}<0.1 \text {. Each column has results from } \\
\text { a separate OLS model with CZs as observations. Dependent vari- } \\
\text { able is the model estimate of a CZ's skill ratio denoted by the col- } \\
\text { umn heading. Dependent variables from model estimation de- } \\
\text { scribed in Section } 6.1 \text { using } 1990 \text { Census and NELS: } 88 \text {. ln }\left(K_{j g}\right) \\
\text { is CZ's log child skill ratio. } \ln \left(S_{j g}\right) \text { is CZ's log adult skill ra- } \\
\text { tio. Major metro area is the omitted CZ size category. West is } \\
\text { the omitted CZ region. See text for definitions of other variables. } \\
\text { Heteroskedasticity-robust standard errors in parentheses. Num- } \\
\text { bers of observations are rounded to the nearest ten, since the data } \\
\text { are restricted. }\end{array}$} \\
\hline
\end{tabular}




\section{A Data appendix}

\section{A.1 Commuting zones and their characteristics}

Tolbert and Sizer (1996) describe the procedure they used to create the CZ classification. CZs were defined using confidential 1990 Census journey-to-work data. They are clusters of counties or county equivalents (boroughs, parishes, Census areas, and independent cities) with particularly strong commuting ties. There are 741 of them. CZs cross state lines and cover the entire United States (unlike alternative geographic units like MSAs).

Tolbert and Sizer (1996) provide some useful characterizations of CZs. They categorize CZs into four regions of the U.S.: Northeast, South, Midwest, and West. They also classify CZs as falling into one of six categories: small town, small urban, large urban, small metro, medium metro, and major metro. These are descriptions of the largest population center in each CZ. Small towns have fewer than 5,000 residents, small urban centers have between 5,000 and 20,000, and larger urban centers have at least 20,000 but no MSAs in the $\mathrm{CZ}$. The remaining three categories are CZs with at least one MSA in their territory. They are classified according to the size of the largest MSA, where small metro centers have fewer than 250,000 residents, medium metro centers have between 250,000 and 1 million, and major metro centers have more than 1 million. These population figures refer to 1990.

I obtain additional characteristics of CZs from the 5 percent samples of the 1990 and 2000 Census (Ruggles et al. 2004). I follow Autor and Dorn (2008) in matching Census

data to CZs. The least aggregated geographic unit identifiable in the 1990 and 20005 percent samples from IPUMS is the public use microdata area (PUMA). These are county clusters and are on average smaller than CZs. However, there exist PUMAs that overlap CZ boundaries. In order to match the two classifications, I weight average characteristics of PUMAs according to 2000 county populations when attributing those characteristics to a CZ. More specifically, I break down CZs into their individual counties. I assign to each county the average characteristic in the county's PUMA. I then create the CZ average 
characteristic by taking the weighted average of county characteristics, where the weights are the proportion of $\mathrm{CZ}$ residents residing in each county.

The CZ characteristics derived from the 2000 Census are the following:

- Percent with at least a bachelor's degree. The population here is restricted to those at least 24 years old and no older than 64 .

- Average weekly wage. The population here is restricted to those currently employed and at least 16 years old and no older than 64 . I weight by a labor supply variable, which is weeks worked in the previous year times usual weekly hours. For those with missing values of these variables, I impute labor supply as the average in their education-occupation cell, or just their education cell if the previous includes only themselves. I take wage and salary income from the previous year as the baseline earnings measure. I multiply top-coded ( $\$ 175,000$ in 2000) values by 1.5 . The weekly wage is the resulting number divided by weeks worked.

- Percent employed in the manufacturing industry. These are workers with 2000 Census industry codes between 107 and 399, inclusive. The population includes only those working positive hours in the previous year.

All samples are restricted to include only non-institutionalized residents. I also create a similar data set from the 1990 Census, using the same methods and definitions as much as possible.

I assign a latitude and longitude to each CZ. I acquire latitude and longitude of ZIP code tabulation areas (ZCTAs) from the U.S. Census Bureau. These correspond roughly with zip codes. I then assign zip codes to CZs, using a zip code file purchased from ZipInfo.com and counties as the merging variable. I assign to each $\mathrm{CZ}$ the latitude that is the midpoint between the minimum and maximum latitudes of zip codes in that CZ. I assign CZ longitudes similarly.

I use these latitudes and longitudes to calculate distances between CZs. The distance measure I use is the great circle distance between coordinates, in kilometers. 


\section{A.2 NELS:88}

The procedure used to match NELS:88 respondents to CZ of residence uses zip code variables in the restricted-use version of the data. I match zip codes to U.S. counties using a commercial crosswalk (ZipInfo.com). Since CZs are collections of counties, it is then straightforward to identify the respondent's CZ. I assign the zip code of the 8th grade

school as the origin of the student and the zip code of residence at the final follow-up (2000) as the final destination. For some respondents, I am not able to identify the CZ due to missing data. Tables A.1 and A.2 compare characteristics of respondents for which I do and do not have $\mathrm{CZ}$ identified. I drop respondents with missing $\mathrm{CZ}$ from the analysis.

Table A.3 indicates that post-secondary schooling still affects the choices of a significant number of NELS:88 respondents in the final follow-up (2000). Twenty-two percent of respondents were attending classes at either an academic or vocational school at the final follow-up. Five percent were attending school and not working at all. The cohort had not all moved on from the school attendance phase of life, and this is a weakness for the purpose of estimating geographic skill distributions from the model. 
Table A.1: Characteristics of Respondents, by Base Year Location Data Status

\begin{tabular}{|c|c|c|c|c|}
\hline \multirow[b]{3}{*}{ Variable } & \multirow{2}{*}{\multicolumn{2}{|c|}{$\begin{array}{c}(1) \quad(2) \\
C Z \text { identified } \\
{[N=11150]}\end{array}$}} & \multirow{2}{*}{\multicolumn{2}{|c|}{$\begin{array}{c}(3) \\
\text { CZ not identified } \\
{[N=240]}\end{array}$}} \\
\hline & & & & \\
\hline & Mean & SE & Mean & SE \\
\hline HS Dropout & .068 & .007 & .08 & .043 \\
\hline College Grad & .294 & .008 & .254 & .042 \\
\hline Test Index & 10.026 & .001 & 10.03 & .004 \\
\hline Predict Log Earnings & 10.188 & .006 & 10.194 & .025 \\
\hline Female & .503 & .011 & .493 & .065 \\
\hline Asian & .035 & .003 & .033 & .01 \\
\hline Hispanic & .104 & .006 & .152 & .044 \\
\hline Black & .131 & .011 & .025 & .009 \\
\hline White & .715 & .011 & .782 & .047 \\
\hline Full-time Work 2000 & .594 & .01 & .606 & .061 \\
\hline Married & 471 & .01 & .42 & .063 \\
\hline Any Kids & .407 & .011 & .357 & .062 \\
\hline Parents Ed & 13.851 & .04 & 13.489 & .412 \\
\hline Parents Income & 41685 & 595 & 41466 & 4113 \\
\hline Parent Pred. Log Earn. & 8.263 & .005 & 8.225 & .047 \\
\hline
\end{tabular}
rounded to the nearest ten, since the data are restricted. 
Table A.2: Characteristics of Respondents, by Final Follow-up (2000) Location Data Status

\begin{tabular}{|c|c|c|c|c|}
\hline \multirow[b]{3}{*}{ Variable } & \multirow{2}{*}{\multicolumn{2}{|c|}{$\begin{array}{c}(1) \quad(2) \\
C Z \text { identified } \\
{[N=11310]}\end{array}$}} & \multirow{2}{*}{\multicolumn{2}{|c|}{$\begin{array}{c}(3) \quad(4) \\
\text { CZ not identified } \\
{[N=70]}\end{array}$}} \\
\hline & & & & \\
\hline & Mean & SE & Mean & SE \\
\hline HS Dropout & .068 & .007 & .021 & .016 \\
\hline College Grad & .293 & .008 & .467 & .106 \\
\hline Test Index & 10.026 & .001 & 10.037 & .01 \\
\hline Predict Log Earnings & 10.187 & .006 & 10.327 & .051 \\
\hline Female & .504 & .011 & .336 & .087 \\
\hline Asian & .035 & .003 & .028 & .013 \\
\hline Hispanic & .106 & .006 & .029 & .014 \\
\hline Black & .129 & .011 & .078 & .037 \\
\hline White & .716 & .011 & .859 & .046 \\
\hline Full-time Work 2000 & .594 & .01 & .66 & .087 \\
\hline Married & .469 & .01 & .615 & .099 \\
\hline Any Kids & .406 & .011 & .426 & .117 \\
\hline Parents Ed & 13.839 & .04 & 14.549 & .293 \\
\hline Parents Income & 41606 & 590 & 53121 & 8789 \\
\hline Parent Pred. Log Earn. & 8.261 & .005 & 8.346 & .038 \\
\hline
\end{tabular}
rounded to the nearest ten, since the data are restricted. 
Table A.3: School Attendance at Final Follow-Up, NELS:88

\begin{tabular}{lcc}
\hline \hline & $(1)$ & $\begin{array}{c}(2) \\
\text { Proportion }\end{array}$ \\
\cline { 2 - 3 } Total respondents & 11080 & 1 \\
In school (final follow-up) & 2410 & .22 \\
In school and PT work & 1350 & .12 \\
In school and FT work & 690 & .06 \\
In school and no work & 530 & .05 \\
\hline Notes: Numbers of observations ( $N$ above) are \\
rounded to the nearest ten, since the data are re- \\
stricted.
\end{tabular}




\section{A.3 Parent earnings predictions with the PSID}

This section describes how I use PSID data to predict permanent earnings of NELS:88 parents. The PSID began with a survey of U.S. residents in 1968 and continues to collect information about their families. I use data describing respondents and families associated with the original cross-sectional sample (the SRC sample), not including the oversample of low-income families (the SEO sample). I extract data for all years from 1968 to 1996, keeping respondents at least 18 years old who were born from 1935 to 1955 and who worked at least 1,400 hours in the previous year. This cohort corresponds with birth years of most NELS:88 parents.

I categorize the 1970 Census occupation codes reported in the PSID into the coarser occupation definitions in the NELS:88. The occupation titles are: office worker, tradesperson, farmer/farm manager, laborer, manager, military, operator of machines or tools, bachelors degree professional, graduate degree professional, owner of a small business, protective service, sales, school teacher, service worker, and technical. I assign a single occupation to each respondent, using the occupation category reported for the most years. To break ties, I take the occupation held latest in life.

The earnings measure I use is the log of annual income from labor. I adjust for inflation using the CPI-U with base year 1982-1984. For each respondent, I derive an estimate of permanent earnings as follows: I regress log annual earnings on age, age squared, and survey year indicators (with no constant). The age- and year-adjusted earnings measure for each year is the residual plus the intercept estimate for 1988. The permanent earnings of an individual is the average of his age- and year-adjusted earnings variables.

I then regress permanent earnings on indicators for sex, race, education categories, and occupation categories, plus interactions between occupation and years of education. I use the coefficients estimated from this regression to predict permanent earnings for NELS:88 parents. The average of a students' parent permanent earnings measures is the parent skill index in the NELS:88. Table 6 includes descriptive statistics of the index (labeled "Parent Pred. Log Earn."). 


\section{B Results appendix}

Table B.1: Probits for Skill Level of Child

\begin{tabular}{|c|c|c|c|c|}
\hline & $\begin{array}{c}(1) \\
\text { Low }\end{array}$ & $\begin{array}{c}(2) \\
\text { Medium-Low }\end{array}$ & $\begin{array}{c}\text { (3) } \\
\text { Medium-High }\end{array}$ & $\begin{array}{c}(4) \\
\text { High }\end{array}$ \\
\hline Parent low skill & $.22^{* * *}$ & .0344 & $-.115^{* * *}$ & $-.157^{* * *}$ \\
\hline & $(.0293)$ & $(.0271)$ & $(.0192)$ & $(.0149)$ \\
\hline Parent medium-low skill & $\begin{array}{l}.0652^{* *} \\
(.0257)\end{array}$ & $\begin{array}{c}.0362 \\
(.0223)\end{array}$ & $\begin{array}{c}-.0518^{* *} \\
(.021)\end{array}$ & $\begin{array}{l}-.037^{* * *} \\
(.0182)\end{array}$ \\
\hline Parent high skill & $\begin{array}{c}-.112^{* * * *} \\
(.0199)\end{array}$ & $\begin{array}{c}-.0675^{* * * *} \\
(.0192)\end{array}$ & $\begin{array}{c}-.0456^{* *} \\
(.0195)\end{array}$ & $\begin{array}{l}.188^{* * *} \\
(.0197)\end{array}$ \\
\hline Jan Temp (degF) & $\begin{array}{l}.00287 \\
(.0026)\end{array}$ & $\begin{array}{l}-.00177 \\
(.0024)\end{array}$ & $\begin{array}{c}-.00142 \\
(.00224)\end{array}$ & $\begin{array}{l}.000987 \\
.00185)\end{array}$ \\
\hline July Temp (degF) & $\begin{array}{l}-.00583 \\
(.00858)\end{array}$ & $\begin{array}{l}.00865 \\
(.00558)\end{array}$ & $\begin{array}{l}-.0015 \\
(.00576)\end{array}$ & $\begin{array}{l}-.0013 \\
(.00442)\end{array}$ \\
\hline Ann. Snow (in) & $\begin{array}{l}-.000745 \\
(.000996)\end{array}$ & $\begin{array}{l}.000164 \\
(.00109)\end{array}$ & $\begin{array}{l}-.00075 \\
(.00093)\end{array}$ & $\begin{array}{c}.00135^{*} \\
(.000776)\end{array}$ \\
\hline Wage tax & $\begin{array}{l}-.0061 \\
(.0102)\end{array}$ & $\begin{array}{l}.00129 \\
(.0069)\end{array}$ & $\begin{array}{l}-.00516 \\
(.00903)\end{array}$ & $\begin{array}{c}.0098 \\
(.00628)\end{array}$ \\
\hline Ln(college subsidy) & $\begin{array}{l}.0278 \\
(.0417)\end{array}$ & $\begin{array}{l}-.0417 \\
(.0356)\end{array}$ & $\begin{array}{c}.03 \\
(.0396)\end{array}$ & $\begin{array}{l}-.0186 \\
(.0298)\end{array}$ \\
\hline College enroll/Pop & $\begin{array}{l}.174 \\
(.871)\end{array}$ & $\begin{array}{l}-.0923 \\
(.695)\end{array}$ & $\begin{array}{l}-1.11 \\
(.729)\end{array}$ & $\begin{array}{l}1.18^{*} \\
(.681)\end{array}$ \\
\hline No local college & $\begin{array}{l}-.14^{* *} \\
(.0679)\end{array}$ & $\begin{array}{l}-.0737 \\
(.0936)\end{array}$ & $\begin{array}{l}.165 \\
(.147)\end{array}$ & $\begin{array}{l}-.0206 \\
(.0886)\end{array}$ \\
\hline Ln(avg wkly wage) & $\begin{array}{l}.127 \\
(.323)\end{array}$ & $\begin{array}{c}.182 \\
(.243)\end{array}$ & $\begin{array}{l}-.199 \\
(.219)\end{array}$ & $\begin{array}{l}-.0224 \\
(.176)\end{array}$ \\
\hline$\%$ College Grad & $\begin{array}{c}-.0054 \\
(.00867)\end{array}$ & $\begin{array}{l}.00257 \\
(.00657)\end{array}$ & $\begin{array}{c}.00369 \\
(.00535)\end{array}$ & $\begin{array}{l}-.00297 \\
(.00435)\end{array}$ \\
\hline \% Unemployed & $\begin{array}{l}.0167 \\
(.0131)\end{array}$ & $\begin{array}{l}-.00187 \\
(.00973)\end{array}$ & $\begin{array}{l}.00664 \\
(.00957)\end{array}$ & $\begin{array}{c}-.0235^{* * *} \\
(.0077)\end{array}$ \\
\hline$\%$ Manufacturing & $\begin{array}{l}.00135 \\
(.0043)\end{array}$ & $\begin{array}{l}-.00334 \\
(.00293)\end{array}$ & $\begin{array}{c}.00108 \\
(.00294)\end{array}$ & $\begin{array}{l}.000981 \\
.00201)\end{array}$ \\
\hline Ln(population) & $\begin{array}{l}.00392 \\
(.0281)\end{array}$ & $\begin{array}{l}.00135 \\
(.0186)\end{array}$ & $\begin{array}{l}-.0105 \\
(.0189)\end{array}$ & $\begin{array}{l}.00653 \\
(.0165)\end{array}$ \\
\hline ParLow $\times$ Jan Temp & $\begin{array}{l}-.000641 \\
(.00353)\end{array}$ & $\begin{array}{l}-.000288 \\
(.00338)\end{array}$ & $\begin{array}{l}-.00163 \\
(.00309)\end{array}$ & $\begin{array}{l}.00208 \\
(.00282)\end{array}$ \\
\hline ParLow $\times$ July Temp & $\begin{array}{l}.00553 \\
(.0105)\end{array}$ & $\begin{array}{c}.00334 \\
(.00923)\end{array}$ & $\begin{array}{l}-.00225 \\
(.00746)\end{array}$ & $\begin{array}{c}-.0137^{*} \\
(.00709)\end{array}$ \\
\hline ParLow $\times$ Snow & $\begin{array}{l}.000528 \\
(.00174)\end{array}$ & $\begin{array}{l}.000817 \\
(.00167)\end{array}$ & $\begin{array}{l}.0000731 \\
(.00142)\end{array}$ & $\begin{array}{l}-.00133 \\
(.00119)\end{array}$ \\
\hline
\end{tabular}


Table B.1 - continued from previous page

\begin{tabular}{|c|c|c|c|c|}
\hline & Low & Medium-Low & Medium-High & High \\
\hline \multirow[t]{2}{*}{ ParLow $\times$ Tax } & .0204 & -.014 & .00274 & -.0111 \\
\hline & $(.014)$ & $(.0136)$ & (.0127) & (.0108) \\
\hline \multirow{2}{*}{ ParLow $\times \operatorname{Ln}($ col subsidy $)$} & $-.111^{*}$ & $.122^{*}$ & .00701 & .000338 \\
\hline & $(.06)$ & $(.0622)$ & $(.0585)$ & $(.0524)$ \\
\hline \multirow[t]{2}{*}{ ParLow $\times$ Col enroll/Pop } & -1.53 & -.227 & $1.99^{* *}$ & .5 \\
\hline & $(1.15)$ & $(1.08)$ & $(.97)$ & $(.93)$ \\
\hline \multirow[t]{2}{*}{ ParLow $\times$ No college } & .11 & -.115 & .0375 & .0795 \\
\hline & $(.203)$ & $(.158)$ & $(.184)$ & $(.138)$ \\
\hline \multirow[t]{2}{*}{ ParLow $\times \log ($ wkly wage $)$} & -.212 & -.196 & .427 & -.125 \\
\hline & $(.413)$ & $(.378)$ & $(.331)$ & $(.28)$ \\
\hline \multirow[t]{2}{*}{ ParLow $\times$ College grad } & .00655 & .00707 & $-.0149^{*}$ & -.00238 \\
\hline & $(.0106)$ & $(.00847)$ & $(.00804)$ & $(.0077)$ \\
\hline \multirow{2}{*}{ ParLow $\times$ Unemployed } & -.00255 & -.000487 & -.0135 & .00153 \\
\hline & $(.0165)$ & $(.015)$ & $(.0133)$ & $(.0118)$ \\
\hline \multirow{2}{*}{ ParLow $\times$ Manufacture } & -.00107 & .00407 & -.00334 & .000895 \\
\hline & (.00506) & $(.00378)$ & (.00378) & $(.00325)$ \\
\hline \multirow{2}{*}{ ParLow $\times \log ($ pop $)$} & .0166 & -.0184 & -.00149 & .00849 \\
\hline & $(.0351)$ & $(.0275)$ & $(.0286)$ & $(.0263)$ \\
\hline \multirow[t]{2}{*}{ ParMedLow $\times$ Jan Temp } & .00113 & .000023 & .00129 & -.00388 \\
\hline & $(.0037)$ & $(.00388)$ & $(.00313)$ & $(.00279)$ \\
\hline \multirow[t]{2}{*}{ ParMedLow $\times$ July Temp } & .00869 & -.00737 & -.0059 & .0046 \\
\hline & $(.0105)$ & $(.00728)$ & $(.00717)$ & $(.00666)$ \\
\hline \multirow[t]{2}{*}{ ParMedLow $\times$ Snow } & .00193 & -.000673 & -.000869 & -.000648 \\
\hline & (.00149) & $(.00157)$ & (.00139) & $(.00133)$ \\
\hline \multirow[t]{2}{*}{ ParMedLow $\times$ Tax } & .0039 & .00482 & .00627 & -.0153 \\
\hline & $(.0136)$ & $(.00981)$ & $(.0121)$ & (.0101) \\
\hline \multirow[t]{2}{*}{ ParMedLow $\times$ Ln(col subsidy) } & -.0258 & .0379 & -.0358 & .0237 \\
\hline & $(.0666)$ & $(.0528)$ & $(.0563)$ & $(.0514)$ \\
\hline \multirow[t]{2}{*}{ ParMedLow $\times$ Col enroll/Pop } & .411 & -.591 & 1.16 & -1.17 \\
\hline & $(1.07)$ & $(.939)$ & $(.923)$ & $(.868)$ \\
\hline \multirow[t]{2}{*}{ ParMedLow $\times$ No college } & .0111 & .0818 & -.0812 & .116 \\
\hline & $(.162)$ & (.145) & $(.151)$ & $(.126)$ \\
\hline \multirow[t]{2}{*}{ ParMedLow $\times \log ($ wkly wage $)$} & .645 & $-.649^{*}$ & -.0465 & -.126 \\
\hline & $(.512)$ & $(.34)$ & $(.329)$ & $(.301)$ \\
\hline \multirow[t]{2}{*}{ ParMedLow $\times$ College grad } & -.0039 & .00119 & .000144 & .00584 \\
\hline & $(.0104)$ & $(.00825)$ & $(.00781)$ & $(.00724)$ \\
\hline \multirow[t]{2}{*}{ ParMedLow $\times$ Unemployed } & -.0147 & .00199 & -.0064 & $.022^{*}$ \\
\hline & $(.0173)$ & $(.0142)$ & $(.0139)$ & $(.0114)$ \\
\hline \multirow[t]{2}{*}{ ParMedLow $\times$ Manufacture } & .00108 & -.00207 & .000132 & .00139 \\
\hline & $(.00492)$ & $(.0037)$ & $(.00362)$ & $(.003)$ \\
\hline \multirow[t]{2}{*}{ ParMedLow $\times \log ($ pop $)$} & -.0584 & .0364 & .0335 & -.0068 \\
\hline & $(.0405)$ & $(.0276)$ & $(.0289)$ & $(.0272)$ \\
\hline
\end{tabular}


Table B.1 - continued from previous page

\begin{tabular}{|c|c|c|c|c|}
\hline & Low & Medium-Low & Medium-High & High \\
\hline ParHigh $\times$ Jan Temp & $\begin{array}{l}-.00137 \\
(.00354)\end{array}$ & $\begin{array}{l}.000204 \\
(.00302)\end{array}$ & $\begin{array}{c}.00385 \\
(.00279)\end{array}$ & $\begin{array}{l}-.00301 \\
(.00237)\end{array}$ \\
\hline ParHigh $\times$ July Temp & $\begin{array}{l}.00436 \\
.00997)\end{array}$ & $\begin{array}{l}-.0101 \\
(.00705)\end{array}$ & $\begin{array}{l}-.00507 \\
(.0067)\end{array}$ & $\begin{array}{l}.00765 \\
(.0056)\end{array}$ \\
\hline ParHigh $\times$ Snow & $\begin{array}{l}.0000451 \\
(.00159)\end{array}$ & $\begin{array}{l}-.000683 \\
(.00144)\end{array}$ & $\begin{array}{c}.00138 \\
(.00121)\end{array}$ & $\begin{array}{l}-.00142 \\
(.00107)\end{array}$ \\
\hline ParHigh $\times$ Tax & $\begin{array}{l}.0363^{* * *} \\
(.013)\end{array}$ & $\begin{array}{l}-.00311 \\
(.0106)\end{array}$ & $\begin{array}{l}.00815 \\
.0108)\end{array}$ & $\begin{array}{l}-.025^{* * * *} \\
(.00858)\end{array}$ \\
\hline ParHigh $\times$ Ln(col subsidy) & $\begin{array}{l}-.0756 \\
(.064)\end{array}$ & $\begin{array}{l}.0183 \\
(.0541)\end{array}$ & $\begin{array}{l}-.0114 \\
(.0508)\end{array}$ & $\begin{array}{c}.0373 \\
(.0431)\end{array}$ \\
\hline ParHigh $\times$ Col enroll/Pop & $\begin{array}{l}.827 \\
(1.1)\end{array}$ & $\begin{array}{l}.49 \\
(.923)\end{array}$ & $\begin{array}{l}1.16 \\
(.904)\end{array}$ & $\begin{array}{c}-1.97^{* *} \\
(.851)\end{array}$ \\
\hline ParHigh $\times$ No college & $\begin{array}{l}.48^{* *} \\
(.203)\end{array}$ & $\begin{array}{c}-.0224 \\
(.16)\end{array}$ & $\begin{array}{l}.056 \\
.(165)\end{array}$ & $\begin{array}{l}-.267^{*} \\
(.137)\end{array}$ \\
\hline ParHigh $\times \log ($ wkly wage $)$ & $\begin{array}{l}-.091 \\
(.398)\end{array}$ & $\begin{array}{l}-.414 \\
(.296)\end{array}$ & $\begin{array}{l}-.0912 \\
(.278)\end{array}$ & $\begin{array}{l}.342 \\
(.232)\end{array}$ \\
\hline ParHigh $\times$ College grad & $\begin{array}{l}-.00817 \\
(.0106)\end{array}$ & $\begin{array}{l}-.00105 \\
(.00871)\end{array}$ & $\begin{array}{l}-.00708 \\
(.00697)\end{array}$ & $\begin{array}{l}.0113^{*} \\
(.0061)\end{array}$ \\
\hline ParHigh $\times$ Unemployed & $\begin{array}{c}-.0417^{* *} \\
(.0186)\end{array}$ & $\begin{array}{c}-.00729 \\
(.014)\end{array}$ & $\begin{array}{l}-.00664 \\
(.0135)\end{array}$ & $\begin{array}{l}.0414^{* * * *} \\
(.0114)\end{array}$ \\
\hline ParHigh $\times$ Manufacture & $\begin{array}{l}-.00367 \\
(.00485)\end{array}$ & $\begin{array}{c}.00158 \\
(.00381)\end{array}$ & $\begin{array}{l}-.00264 \\
(.00383)\end{array}$ & $\begin{array}{l}.00246 \\
(.0029)\end{array}$ \\
\hline ParHigh $\times \log ($ pop $)$ & $\begin{array}{c}.0406 \\
(.0368)\end{array}$ & $\begin{array}{c}.0137 \\
(.0249)\end{array}$ & $\begin{array}{l}.0388 \\
(.0253)\end{array}$ & $\begin{array}{c}-.0576^{* * * *} \\
(.0218)\end{array}$ \\
\hline Observations & 11080 & 11080 & 11080 & 11080 \\
\hline Pseudo $R^{2}$ & 0.0868 & 0.0244 & 0.0237 & 0.0970 \\
\hline
\end{tabular}


Table B.2: Destination CZ Choice Logit, Low Skilled

\begin{tabular}{|c|c|c|c|}
\hline VARIABLES & $\begin{array}{c}(1) \\
\text { No interaction }\end{array}$ & $\begin{array}{c}(2) \\
\text { Home } \times \\
\end{array}$ & $\begin{array}{c}\text { (3) } \\
\text { Rural Origin } \times \\
\end{array}$ \\
\hline $\ln (\bar{W})$ & $\begin{array}{c}.667 \\
(.959)\end{array}$ & & \\
\hline Home & $\begin{array}{l}13.9^{* * *} \\
(4.85)\end{array}$ & & \\
\hline South & $\begin{array}{l}.816^{* * *} \\
(.296)\end{array}$ & $\begin{array}{l}-.733 \\
(.533)\end{array}$ & $\begin{array}{l}.191 \\
(.468)\end{array}$ \\
\hline Midwest & $\begin{array}{l}1.29^{* * *} \\
(.327)\end{array}$ & $\begin{array}{c}-1.87^{* * *} \\
(.554)\end{array}$ & $\begin{array}{l}-.0362 \\
(.401)\end{array}$ \\
\hline West & $\begin{array}{l}1.14^{*} \\
(.619)\end{array}$ & $\begin{array}{c}-2.58^{* * * *} \\
(.533)\end{array}$ & $\begin{array}{l}.613 \\
(.734)\end{array}$ \\
\hline Ocean coast & $\begin{array}{l}-.52^{*} \\
(.276)\end{array}$ & $\begin{array}{l}-.147 \\
(.398)\end{array}$ & $\begin{array}{l}.0799 \\
(.488)\end{array}$ \\
\hline Small town & $\begin{array}{l}-.408 \\
(.894)\end{array}$ & $\begin{array}{c}.671 \\
(1.25)\end{array}$ & $\begin{array}{l}-.592 \\
(1.49)\end{array}$ \\
\hline Small urban & $\begin{array}{l}.0524 \\
(.69)\end{array}$ & $\begin{array}{l}-.469 \\
(.828)\end{array}$ & $\begin{array}{r}-.478 \\
(1.1)\end{array}$ \\
\hline Large urban & $\begin{array}{l}-.307 \\
(.544)\end{array}$ & $\begin{array}{c}.67 \\
(.755)\end{array}$ & $\begin{array}{l}-.329 \\
(.941)\end{array}$ \\
\hline Small metro & $\begin{array}{l}-.0498 \\
(.572)\end{array}$ & $\begin{array}{c}-.0383 \\
(.64)\end{array}$ & $\begin{array}{l}-.461 \\
(.873)\end{array}$ \\
\hline Medium metro & $\begin{array}{c}.33 \\
(.325)\end{array}$ & $\begin{array}{l}-.31 \\
(.408)\end{array}$ & $\begin{array}{l}.0602 \\
(.673)\end{array}$ \\
\hline Jan temp & $\begin{array}{l}.06^{* * *} \\
(.0169)\end{array}$ & $\begin{array}{c}-.0656^{* * *} \\
(.0241)\end{array}$ & $\begin{array}{c}-.0578^{* *} \\
(.028)\end{array}$ \\
\hline July temp & $\begin{array}{l}-.0297 \\
(.0269)\end{array}$ & $\begin{array}{l}-.0646 \\
(.0415)\end{array}$ & $\begin{array}{l}.134^{* * *} \\
(.0471)\end{array}$ \\
\hline Ann. Snow & $\begin{array}{l}-.00152 \\
(.00779)\end{array}$ & $\begin{array}{l}-.0275^{* * *} \\
(.00887)\end{array}$ & $\begin{array}{l}.0182^{*} \\
(.0101)\end{array}$ \\
\hline Wage tax & $\begin{array}{l}-.0399 \\
(.0487)\end{array}$ & $\begin{array}{c}.124 \\
(.0783)\end{array}$ & $\begin{array}{c}.0457 \\
(.0718)\end{array}$ \\
\hline Ln(college subsidy) & $\begin{array}{l}-.81^{* * *} \\
(.305)\end{array}$ & $\begin{array}{l}.395 \\
(.43)\end{array}$ & $\begin{array}{l}.636^{*} \\
(.362)\end{array}$ \\
\hline College enroll/Pop & $\begin{array}{l}2.17^{*} \\
(1.13)\end{array}$ & $\begin{array}{l}-1.22 \\
(4.53)\end{array}$ & $\begin{array}{l}-7.47^{*} \\
(4.22)\end{array}$ \\
\hline No college & $\begin{array}{c}1.42 \\
(1.08)\end{array}$ & $\begin{array}{l}-.792 \\
(.875)\end{array}$ & $\begin{array}{l}-2.78^{* *} \\
(1.22)\end{array}$ \\
\hline$\% \mathrm{BA}$ & $\begin{array}{c}.01 \\
(.0143)\end{array}$ & $\begin{array}{c}-.0635^{* *} \\
(.0277)\end{array}$ & $\begin{array}{l}.00154 \\
(.0248)\end{array}$ \\
\hline$\%$ Manufacturing & $\begin{array}{c}.0134 \\
(.0139)\end{array}$ & $\begin{array}{l}-.016 \\
(.0206)\end{array}$ & $\begin{array}{l}-.0167 \\
(.0253)\end{array}$ \\
\hline Ln(population) & $\begin{array}{l}.816^{* * *} \\
(.174)\end{array}$ & $\begin{array}{l}-.278 \\
(.201)\end{array}$ & $\begin{array}{l}-.315 \\
(.219)\end{array}$ \\
\hline Distance & $\begin{array}{l}-.0025^{* * *} \\
(.000311)\end{array}$ & & \\
\hline Distance $^{2}$ & $\begin{array}{c}2.77 \mathrm{e}-07^{* * *} \\
(4.40 \mathrm{e}-08)\end{array}$ & & \\
\hline BY CZ Col enroll/Pop $\times$ Dest. Ln(pop) & $\begin{array}{c}.35 \\
(1.32)\end{array}$ & & \\
\hline BY CZ Col enroll/Pop $\times$ Dest. Ln(col enroll) & $\begin{array}{l}-4.97 \\
(37.9)\end{array}$ & & \\
\hline Observations & 2520 & & \\
\hline
\end{tabular}


Table B.3: Destination CZ Choice Logit, High Skilled

\begin{tabular}{|c|c|c|c|}
\hline VARIABLES & $\begin{array}{c}(1) \\
\text { No interaction }\end{array}$ & $\begin{array}{c}(2) \\
\text { Home } \times\end{array}$ & $\begin{array}{c}(3) \\
\text { Rural Origin } \times \\
\end{array}$ \\
\hline $\ln (\bar{W})$ & $\begin{array}{l}-.659 \\
(.486)\end{array}$ & & \\
\hline Home & $\begin{array}{l}7.15^{* *} \\
(3.33)\end{array}$ & & \\
\hline South & $\begin{array}{l}.403^{*} \\
(.223)\end{array}$ & $\begin{array}{l}-.402 \\
(.391)\end{array}$ & $\begin{array}{l}-.282 \\
(.432)\end{array}$ \\
\hline Midwest & $\begin{array}{l}.238 \\
(.182)\end{array}$ & $\begin{array}{l}-.516^{*} \\
(.29)\end{array}$ & $\begin{array}{c}.00436 \\
(.38)\end{array}$ \\
\hline West & $\begin{array}{l}1.44^{* * *} \\
(.268)\end{array}$ & $\begin{array}{l}-1.2^{* * *} \\
(.351)\end{array}$ & $\begin{array}{l}-.378 \\
(.511)\end{array}$ \\
\hline Ocean coast & $\begin{array}{l}.0838 \\
(.167)\end{array}$ & $\begin{array}{c}-.706^{* * *} \\
(.256)\end{array}$ & $\begin{array}{l}-.506 \\
(.308)\end{array}$ \\
\hline Small town & $\begin{array}{l}-1.11 \\
(.852)\end{array}$ & $\begin{array}{l}-.797 \\
(.92)\end{array}$ & $\begin{array}{l}2.03^{*} \\
(1.1)\end{array}$ \\
\hline Small urban & $\begin{array}{l}-.406 \\
(.585)\end{array}$ & $\begin{array}{c}.1 \\
(.505)\end{array}$ & $\begin{array}{c}.471 \\
(.745)\end{array}$ \\
\hline Large urban & $\begin{array}{l}-.303 \\
(.323)\end{array}$ & $\begin{array}{l}-.506 \\
(.523)\end{array}$ & $\begin{array}{l}.859 \\
(.555)\end{array}$ \\
\hline Small metro & $\begin{array}{c}-.635^{* * *} \\
(.234)\end{array}$ & $\begin{array}{l}.439 \\
(.355)\end{array}$ & $\begin{array}{l}.649 \\
(.414)\end{array}$ \\
\hline Medium metro & $\begin{array}{l}-.0974 \\
(.173)\end{array}$ & $\begin{array}{l}-.0509 \\
(.259)\end{array}$ & $\begin{array}{c}.426 \\
(.283)\end{array}$ \\
\hline Jan temp & $\begin{array}{l}-.000947 \\
(.00849)\end{array}$ & $\begin{array}{c}.0000477 \\
(.0159)\end{array}$ & $\begin{array}{l}-.0235^{*} \\
(.0139)\end{array}$ \\
\hline July temp & $\begin{array}{l}.0137 \\
(.0198)\end{array}$ & $\begin{array}{c}-.00846 \\
(.0258)\end{array}$ & $\begin{array}{c}.023 \\
(.0295)\end{array}$ \\
\hline Ann. Snow & $\begin{array}{l}-.00353 \\
(.00374)\end{array}$ & $\begin{array}{l}-.00807 \\
(.0059)\end{array}$ & $\begin{array}{c}.00791 \\
(.00611)\end{array}$ \\
\hline Wage tax & $\begin{array}{c}-.0647^{* *} \\
(.0294)\end{array}$ & $\begin{array}{l}.139^{* * *} \\
(.0514)\end{array}$ & $\begin{array}{l}-.0151 \\
(.0519)\end{array}$ \\
\hline Ln(college subsidy) & $\begin{array}{l}.389^{* *} \\
(.175)\end{array}$ & $\begin{array}{l}-.72^{* * *} \\
(.255)\end{array}$ & $\begin{array}{l}.231 \\
(.237)\end{array}$ \\
\hline College enroll/Pop & $\begin{array}{c}.76 \\
(.776)\end{array}$ & $\begin{array}{c}2.21 \\
(3.34)\end{array}$ & $\begin{array}{l}-1.62 \\
(2.34)\end{array}$ \\
\hline No college & $\begin{array}{l}.091 \\
(.623)\end{array}$ & $\begin{array}{c}.94 \\
(.752)\end{array}$ & $\begin{array}{l}-.262 \\
(.797)\end{array}$ \\
\hline$\% \mathrm{BA}$ & $\begin{array}{l}.0745^{* * *} \\
(.0123)\end{array}$ & $\begin{array}{c}-.0866^{* * * *} \\
(.0168)\end{array}$ & $\begin{array}{c}-.0421^{* *} \\
(.0181)\end{array}$ \\
\hline$\%$ Manufacturing & $\begin{array}{l}.0107 \\
(.0104)\end{array}$ & $\begin{array}{l}.0143 \\
(.0158)\end{array}$ & $\begin{array}{l}-.00692 \\
(.0142)\end{array}$ \\
\hline Ln(population) & $\begin{array}{l}.828^{* * *} \\
(.0783)\end{array}$ & $\begin{array}{c}-.399^{* * *} \\
(.11)\end{array}$ & $\begin{array}{l}.15 \\
(.141)\end{array}$ \\
\hline Distance & $\begin{array}{l}-.00224^{* * *} \\
(.000152)\end{array}$ & & \\
\hline Distance $^{2}$ & $\begin{array}{c}2.70 \mathrm{e}-07^{* * *} \\
(1.84 \mathrm{e}-08)\end{array}$ & & \\
\hline BY CZ Col enroll/Pop $\times$ Dest. Ln(pop) & $\begin{array}{l}-.283 \\
(.749)\end{array}$ & & \\
\hline BY CZ Col enroll/Pop $\times$ Dest. Ln(col enroll) & $\begin{array}{l}-13.4 \\
(30.1)\end{array}$ & & \\
\hline Observations & 3070 & & \\
\hline
\end{tabular}


Table B.4: Parameter Estimates for States, Census

\begin{tabular}{|c|c|c|c|c|c|}
\hline & (1) & (2) & (3) & (4) & (5) \\
\hline State & $S_{j g-1}$ & $K_{j g}$ & $K_{j g} \Lambda_{j g}$ & $S_{j g}$ & $\Lambda_{j g} M_{j g}$ \\
\hline Alabama & .7 & .68 & .52 & .67 & .99 \\
\hline Alaska & 1.68 & .81 & .45 & .79 & .98 \\
\hline Arizona & 1.18 & .74 & .54 & 1.09 & 1.47 \\
\hline Arkansas & .65 & .59 & .45 & .55 & .93 \\
\hline California & 1.39 & 1.01 & .99 & 1.33 & 1.31 \\
\hline Colorado & 1.5 & 1.11 & .92 & 1.53 & 1.37 \\
\hline Connecticut & 1.39 & 1.41 & 1.02 & 1.45 & 1.03 \\
\hline Delaware & .93 & 1.03 & .63 & .98 & .95 \\
\hline District of Columbia & .71 & 1.31 & .39 & 1.53 & 1.17 \\
\hline Florida & .88 & .74 & .55 & .88 & 1.19 \\
\hline Georgia & .71 & .64 & .5 & .9 & 1.39 \\
\hline Hawaii & 1.47 & 1.06 & .72 & .92 & .87 \\
\hline Idaho & 1.22 & .98 & .69 & .85 & .87 \\
\hline Illinois & 1.03 & 1.24 & 1.06 & 1.28 & 1.04 \\
\hline Indiana & .79 & .87 & .63 & .75 & .87 \\
\hline Iowa & .98 & 1.25 & .77 & .86 & .69 \\
\hline Kansas & 1.17 & 1.13 & .85 & 1.1 & .97 \\
\hline Kentucky & .71 & .71 & .52 & .64 & .9 \\
\hline Louisiana & .83 & .64 & .45 & .56 & .87 \\
\hline Maine & .84 & .83 & .5 & .74 & .89 \\
\hline Maryland & 1.05 & .96 & .69 & 1.18 & 1.23 \\
\hline Massachusetts & 1.23 & 1.63 & 1.37 & 1.76 & 1.08 \\
\hline Michigan & 1 & 1.08 & .85 & .92 & .85 \\
\hline Minnesota & 1.25 & 1.4 & 1.13 & 1.36 & .98 \\
\hline Mississippi & .61 & .53 & .39 & .49 & .92 \\
\hline Missouri & .85 & .97 & .7 & .85 & .88 \\
\hline Montana & 1.16 & 1.14 & .68 & .72 & .64 \\
\hline Nebraska & 1.12 & 1.32 & 1 & 1.05 & .8 \\
\hline Nevada & .81 & .78 & .55 & .7 & .9 \\
\hline New Hampshire & 1.18 & .99 & .69 & 1.18 & 1.19 \\
\hline New Jersey & 1.18 & 1.44 & 1.14 & 1.47 & 1.02 \\
\hline New Mexico & 1.06 & .73 & .42 & .74 & 1.02 \\
\hline New York & 1.13 & 1.46 & 1.12 & 1.27 & .87 \\
\hline North Carolina & .6 & .65 & .51 & .81 & 1.24 \\
\hline North Dakota & 1.13 & 1.33 & .79 & .85 & .64 \\
\hline Ohio & .91 & .99 & .73 & .85 & .86 \\
\hline Oklahoma & .99 & .96 & .64 & .71 & .74 \\
\hline Oregon & 1.25 & .91 & .73 & .96 & 1.05 \\
\hline Pennsylvania & .86 & 1.09 & .74 & .87 & .8 \\
\hline Rhode Island & .96 & 1.27 & .88 & 1.12 & .89 \\
\hline South Carolina & .56 & .55 & .38 & .61 & 1.11 \\
\hline South Dakota & 1.15 & 1.14 & .7 & .78 & .68 \\
\hline Tennessee & .69 & .71 & .52 & .7 & 1 \\
\hline Texas & 1 & .73 & .65 & .95 & 1.31 \\
\hline Utah & 1.52 & 1.3 & 1.08 & 1.28 & .99 \\
\hline Vermont & 1.13 & .82 & .47 & .92 & 1.12 \\
\hline Virginia & .95 & .79 & .53 & 1.15 & 1.47 \\
\hline Washington & 1.38 & 1.08 & .95 & 1.21 & 1.12 \\
\hline West Virginia & .9 & .77 & .51 & .57 & .74 \\
\hline Wisconsin & .97 & 1.18 & .85 & .92 & .78 \\
\hline Wyoming & 1.31 & .99 & .51 & .67 & .68 \\
\hline
\end{tabular}




\section{Model estimation with the NELS:88 and states as loca- tions}

Model estimation with states as locations is an aggregation of the method applied to CZs. The model estimation described above yields estimates for each CZ of the high- and lowskilled populations of a first generation as adults, a second generation as children, those children who stayed in their origins, and the second generation as adults. I sum each of these populations within states to get state populations of high- and low-skilled people. ${ }^{31}$ I then take ratios to calculate $S_{j g-1}, K_{j g}, K_{j g} \Lambda_{j g}$ and $S_{j g}$ for each state $j$. I calculate $\Lambda_{j g}=\left(K_{j g} \Lambda_{j g}\right) / K_{j g}$ and $M_{j g}=S_{j g-1} /\left(K_{j g} \Lambda_{j g}\right)$. For this state-level exercise, I use model estimates of all $741 \mathrm{CZs}$, in contrast to the above analysis of approximately $310 \mathrm{CZs}$ in the NELS:88 sample.

Tables C.1 and C.2 show the resulting estimates. Table C.1 displays summary statistics of model estimates describing the distribution of skills across states. These estimates are similar to those from the Census accounting exercise (Table 2). One difference is that the increase in skewness from child to adult skill distributions comes both through differential native retention and in-migration with the NELS:88, rather than just the former in the Census. The skewness of $\Lambda_{j g}$ is negative with the Census but positive in the model estimation. The ranges of $\Lambda_{j g}$ and $M_{j g}$ are similar between the two methods, except that the maximum $M_{j g}$ from the NELS:88 method is substantially higher than the maximum from the Census.

Table C. 2 lists correlations between model components that are comparable to those in Table 3 from the Census accounting exercise. There are some differences, but they seem less notable than the similarities. The largest difference is that the correlation between $M_{j g}$ and $K_{j g} / S_{j g-1}$ changes sign. The main correlations of interest are similar between the two tables. In particular, the correlation between parent skills $\left(S_{j g-1}\right)$ and skill gains through

\footnotetext{
${ }^{31}$ For CZs crossing state lines, I assign their populations to the state with the higher share of CZ population.
} 
intergenerational transmission $K_{j g} / S_{j g-1}$ is negative and very similar in both specifications. Also, the correlation between $S_{j g-1}$ and skill gains through migration $\left(\Lambda_{j g} M_{j g}\right)$ is close to zero.

In general, model estimation with the NELS:88 induces more variability in estimates of the geographic mobility of skills than is present in the Census accounting exercise. This is perhaps to be expected, since there is an extra layer of estimation from the model, relative to the Census method, and the underlying sample for measuring migration and intergenerational transmission is smaller than the Census sample. However, the NELS:88 approach has enough precision to replicate findings in the Census and add to the understanding of the geographic distribution of human capital. 
Table C.1: Accounting for Skills across States, NELS:88

\begin{tabular}{llccccc}
\hline \hline & & $(1)$ & $(2)$ & $(3)$ & $(4)$ & $(5)$ \\
Description & Variable & Mean & StDev & Skew & Min & Max \\
\cline { 2 - 7 } Parent gen. skill ratio & $S_{j g-1}$ & 1 & .26 & 1.06 & .64 & 1.87 \\
Child skill ratio & $K_{j g}$ & 1.18 & .34 & .55 & .65 & 2.02 \\
Stayers skill ratio & $K_{j g} \Lambda_{j g}$ & .76 & .25 & .88 & .3 & 1.49 \\
Adult skill ratio & $S_{j g}$ & 1.14 & .42 & 1.59 & .57 & 2.71 \\
& & & & & & \\
Intergenerational factor & $K_{j g} / S_{j g-1}$ & 1.2 & .36 & 2.01 & .64 & 2.73 \\
Native retention factor & $\Lambda_{j g}$ & .64 & .11 & 1.21 & .46 & 1.02 \\
In-migration factor & $M_{j g}$ & 1.6 & .82 & 5.46 & .99 & 6.91 \\
Total migration factor & $\Lambda_{j g} M_{j g}$ & 1 & .38 & 4.06 & .53 & 3.21 \\
\hline
\end{tabular}

Table C.2: Correlations between Accounting Exercise Characteristics of States, NELS:88

\begin{tabular}{lcccccccc}
\hline \hline & $(1)$ & $(2)$ & $(3)$ & $(4)$ & $(5)$ & $(6)$ & $(7)$ & $(8)$ \\
& $S_{j g-1}$ & $K_{j g}$ & $K_{j g} \Lambda_{j g}$ & $S_{j g}$ & $K_{j g} / S_{j g-1}$ & $\Lambda_{j g}$ & $M_{j g}$ & $\Lambda_{j g} M_{j g}$ \\
\cline { 2 - 9 }$S_{j g-1}$ & 1 & & & & & & & \\
$K_{j g}$ & .527 & 1 & & & & & & \\
$K_{j g} \Lambda_{j g}$ & .582 & .844 & 1 & & & & & \\
$S_{j g}$ & .558 & .554 & .591 & 1 & & & & \\
$K_{j g} / S_{j g-1}$ & -.324 & .617 & .375 & .097 & 1 & & & \\
$\Lambda_{j g}$ & .211 & -.055 & .462 & .112 & -.266 & 1 & & \\
$M_{j g}$ & -.087 & -.238 & -.32 & .474 & -.186 & -.319 & 1 & \\
$\Lambda_{j g} M_{j g}$ & .008 & -.272 & -.168 & .574 & -.309 & .039 & .928 & 1 \\
\hline
\end{tabular}

